\title{
Control structure design for resource recovery using the enhanced biological phosphorus removal and recovery (EBP2R) activated sludge process
}

Valverde Perez, Borja; Fuentes-Martínez, José Manuel ; Flores Alsina, Xavier; Gernaey, Krist; Huusom, Jakob Kjøbsted; Plósz, Benedek G.

\section{Published in:}

Chemical Engineering Journal

Link to article, DOI:

10.1016/j.cej.2016.03.021

Publication date:

2016

Document Version

Peer reviewed version

Link back to DTU Orbit

Citation (APA):

Valverde Perez, B., Fuentes-Martínez, J. M., Flores Alsina, X., Gernaey, K., Huusom, J. K., \& Plósz, B. G. (2016). Control structure design for resource recovery using the enhanced biological phosphorus removal and recovery (EBP2R) activated sludge process. Chemical Engineering Journal, 296, 447-457.

https://doi.org/10.1016/j.cej.2016.03.021

\section{General rights}

Copyright and moral rights for the publications made accessible in the public portal are retained by the authors and/or other copyright owners and it is a condition of accessing publications that users recognise and abide by the legal requirements associated with these rights.

- Users may download and print one copy of any publication from the public portal for the purpose of private study or research.

- You may not further distribute the material or use it for any profit-making activity or commercial gain

- You may freely distribute the URL identifying the publication in the public portal 


\title{
Control structure design for resource recovery using the enhanced biological phosphorus removal and recovery (EBP2R) activated sludge process
}

Borja Valverde-Pérez ${ }^{\mathrm{a}^{*}}$, José Manuel Fuentes-Martínez ${ }^{\mathrm{a}}$, Xavier Flores-Alsina ${ }^{\mathrm{b}}$, Krist V. Gernaey ${ }^{\mathrm{b}}$, Jakob Kjøbsted Huusom ${ }^{\mathrm{b}}$, Benedek Gy. Plósz ${ }^{\mathrm{a}^{* *}}$

${ }^{a}$ Department of Environmental Engineering, Technical University of Denmark, Miljøvej, Building 115, DK-2800, Kgs.

Lyngby,Denmark (bvape@env.dtu.dk, beep@env.dtu.dk)

${ }^{b}$ Department of Chemical and Biochemical Engineering, Technical University of Denmark, Søltofts Plads, Building

229, DK-2800, Kgs. Lyngby, Denmark

\begin{abstract}
Nowadays, wastewater is considered as a set of resources to be recovered rather than a mixture of pollutants that should be removed. Many resource recovery schemes have been proposed, involving the use of novel technologies whose controllability is poorly studied. In this paper we present a control structure for the novel enhanced biological phosphorus removal and recovery (EBP2R) process, which is currently under development. The aim of the EBP2R is to maximize phosphorus recovery through optimal green micro-algal cultivation, which is achieved by controlling the nitrogen to phosphorus ratio (N-to-P ratio) fed to the algae. Process control structures are developed for a sequencing batch reactor (SBR) and a continuous flow reactor system (CFS). Results, obtained using the Benchmark Simulation Model No. 1 (BSM1) dynamic input disturbance time series, suggest that the SBR can maintain a stable N-to-P ratio in the effluent $(16.9 \pm 0.07)$ and can recover about $72 \%$ of the influent phosphorus. The phosphorus recovered by the CFS is limited by the influent nitrogen (65\% of the influent phosphorus load). Using the CFS configuration the effluent $\mathrm{N}$-to-P ratio cannot be effectively controlled (16.45 \pm 2.48$)$. Therefore, it is concluded that the SBR is the most effective reactor configuration for the EBP2R process. Importantly, the designed control structures rely on control loops that do not require chemical dosing for nutrient management, thereby reducing the environmental footprint of the EBP2R process. The proposed control strategies can be applied to other phosphorus recovery schemes where short sludge age EBPR systems play an important role.
\end{abstract}

Keywords: wastewater treatment; biochemical phosphorus and nitrogen recovery; process control design; green micro-algae cultivation; process modelling.

\section{Abbreviations:}

ASM2d Activated sludge model 2d

BSM1 Benchmark Simulation Model No. 1

CANR Completely autotrophic nitrogen removal

CAS Conventional activated sludge

CFS Continuous flow system

COD Chemical oxygen demand

CV Controlled variable

DO Dissolved oxygen

EBPR Enhanced biological phosphorus removal

EBP2R Enhanced biological phosphorus removal and recovery 


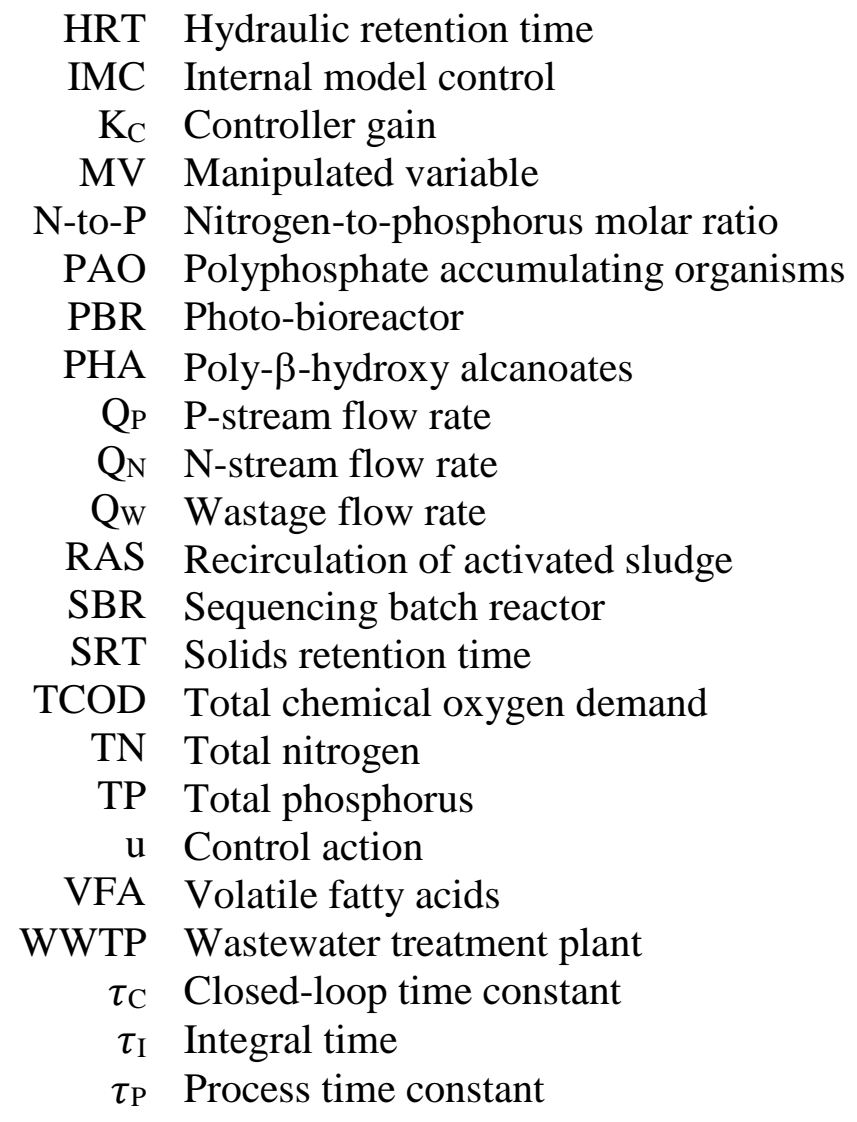

\section{INTRODUCTION}

The available resources are depleting very fast all over our planet due to the increasing population and industrialization (1). As a consequence, current trends in wastewater treatment promote resource recovery, while consider the conventional activated sludge process as a means to destroy resources (2). Under this new paradigm, several strategies and process configurations have been proposed to recover nutrients, energy and water (3). Most of the proposed schemes involve physicochemical processes, such as struvite precipitation, as a mean to recover both nitrogen and phosphorus as a mineral fertilizer (4). Alternatively, energy intensive processes, such as ammonia stripping or reverse osmosis, have been also proposed as resource recovery technologies (3). Due to the environmental burdens of these technologies, derived from their demand for energy and chemicals, there is an increasing interest in using microorganisms to encapsulate the wastewater nutrients (5). A promising option, still under study, is the use of green microalgae as natural fertilizer (6-8). Within this framework, Valverde-Pérez et al. (9) have recently proposed a biological train able to recover nutrients and water through optimal algal cultivation, referred to as the TRENS system. The TRENS system is described as a sequence of an enhanced biological phosphorus removal and recovery (EBP2R) system combined with a photobioreactor (PBR). The EBP2R system is operated at relatively low solids retention time (SRT), so the bulk of nitrogen is kept as ammonia, the preferred nitrogen source for most of the green microalgae (10). The EBP2R is also able to divert a phosphorus-rich stream, referred to as the P-stream, which is combined with the effluent nitrogen, referred to as $\mathrm{N}$-stream, and can be used to construct cultivation medium with 
different optimal nitrogen-to-phosphorus ratios (N-to-P ratio) optimal for a wide range of green micro-algal species. Through the EBP2R, part of the organic carbon is oxidized, whilst the remaining fraction is recovered with the activated sludge and further digested to produce biogas. The fraction of influent nitrogen which cannot be recovered via algal cultivation is removed via the completely autotrophic nitrogen removal (CANR) process. TRENS has been demonstrated to be more sustainable than conventional wastewater treatment based on chemical dosing (11).

Since wastewater treatment plants (WWTPs) were traditionally designed for pollutant removal, most of the proposed control strategies only focus on meeting the effluent quality standards imposed by environmental regulations (12). Several studies aimed to design optimal control structures accounting for other criteria than effluent quality, such as environmental impact or microbiological risks (13-14). However, resource recovery was often disregarded or only partially considered (e.g. fertilizer as a by-product from phosphorus control by adding metal salts). Furthermore, a broad number of control strategies are based on the dosing of chemicals, such as external carbon source to control denitrification or metal salts for phosphorus precipitation (12). Only few studies focus on optimizing the microbial communities in the reactor as a means to reduce external chemical dosage (15).

In the case of algal cultivation, most of the control strategies focus on maximizing the algal productivity by manipulating the hydraulic retention time (HRT), so the culture density does not induce light limitation (16). There is also extensive research on control strategies whereby the $\mathrm{pH}$ is controlled by manipulating the carbon dioxide supply (17). However, nutrient recovery approaches and, more specifically, the TRENS system pose new challenges, as nutrients were often assumed to be supplied in excess (17). Depending on which part of the WWTP the PBR is integrated with, the nutrient balance fed to the algae will be different (18). Therefore, nutrient management becomes more important when the algae are cultivated using wastewater as nutrient and water source. To overcome this issue, EBP2R converts wastewater into P- and N-rich resource streams, thereby producing treated effluent optimal for algal cultivation (9). However, the influent quality of WWTPs is highly dynamic, both in terms of flow rate and composition (e.g., $\mathrm{N}$ and P content), and effective process control is required to maintain optimal effluent for downstream microalgal cultivation.

Therefore, the aim of this paper is to design, test and evaluate different control structures to maximize the nutrient recovery via the EBP2R process implemented as both sequencing batch reactor (SBR) and continuous flow system (CFS) configuration. Both configurations are critically compared in terms of maximum phosphorus recovery, effluent quality for downstream algal cultivation and controllability. Since the EBP2R is still under development, the present study offers a chance to combine process controllability as part of the design process (19). Therefore, the outcome of this work could identify future research needs or suggest optimal configurations for future full scale implementation. This work extends the study presented at the PSE15/ESCAPE25 conference (20), where a control structure was proposed for the continuous flow EBP2R system. Since both the anaerobic digester and the CANR system are considered well-stablished processes (21-22), this study focuses only on the innovative EBP2R to be combined with the PBR. 


\section{MATERIALS AND METHODS}

\subsection{SYSTEM DESCRIPTION}

In order to make both the SBR and the CFS configurations comparable the following considerations have been made. For the EBP2R influent quality, the case of a municipal WWTP of 135,000 people equivalent is chosen, with a wastewater pollutant composition as follows: $712 \mathrm{mg}-\mathrm{COD} \cdot \mathrm{L}^{-1}$ of total COD, $54 \mathrm{mg}-\mathrm{N} \cdot \mathrm{L}^{-1}$ of total nitrogen and $9 \mathrm{mg}-\mathrm{P} \mathrm{L}^{-1}$ of total phosphorus (23). The influent flow rate is set to $19,200 \mathrm{~m}^{3} \cdot \mathrm{d}^{-1}$. The SBR is operated at a hydraulic residence time (HRT) of $9 \mathrm{~h}$, based on the minimal HRT found in literature for sequencing batch EBPR systems (24). This HRT includes the settling phases, which are considered as non-reactive for both the batch and the continuous system. The SBR cycles are defined as $10 \mathrm{~min}$ filling phase, $1.5 \mathrm{~h}$ of anaerobic phase, $3.5 \mathrm{~h}$ of aerobic phase, 40 min of settling phase (equally distributed between anaerobic and aerobic settling phases) and 10 min of drawing phase (distributed according to the desired P-stream volume). An operational scheme is shown in SI-1. The total volume of the SBR is $7,200 \mathrm{~m}^{3}$, whilst the volumes for the continuous system are $1,800 \mathrm{~m}^{3}$ split in two anaerobic reactors connected in series and 4,200 $\mathrm{m}^{3}$ for the aerated basin. The recirculation of activated sludge is set as half of the influent flow rate. Importantly, both systems are designed so that the reactive HRT is the same, $7.5 \mathrm{~h}$, and the relation between the anaerobic and the aerobic HRT follows the guidelines proposed by Randal et al. (25).

\subsection{REACTOR MODELING}

\subsubsection{Biochemical modelling}

The EBP2R system is modelled using the activated sludge model ASM2d (26), further adapted by Flores-Alsina et al. (27). This model includes all the bacterial groups expected to be relevant to the EBP2R process, i.e. heterotrophs, nitrifiers and polyphosphate accumulating organisms (PAOs).

\subsubsection{Hydraulic model}

As part of this work, a simulation model for the SBR configuration of the EBP2R process has been developed. The SBR is described as a tank with a variable volume. There are two different reactive phases, anaerobic and aerobic, where the processes from the ASM2d are active. The drawing and feeding phases are modelled as non-reactive processes. The settling phase is modelled as a point settler assuming a separation efficiency of 0.99. Further details about the model implementation can be found in the Supporting Information (SI-1). The SBR further requires the implementation of an upstream buffer tank. This tank is modelled as a non-limited variable volume tank. Whenever the stored volume is larger than twice the default treated volume per batch, the working volume of the SBR is increased by $30 \%$ in the next cycle (28).

The CFS is described as a sequence of two anaerobic tanks, one settler, one aeration basin and a final settler. The reactors are described as continuous flow stirred tank reactors (CSTRs) with constant volume. The secondary clarifiers are modelled using a point settler model assuming as well a separation efficiency of 0.99 . The simulation model is implemented as a modification of the Benchmark Simulation Model No. 1 (BSM1, [27]).

The simulation models are implemented in Matlab-Simulink (The MathWorks, Natick, MA). 


\subsection{CONTROL DESIGN PROCEDURE}

The control structure design is done following the plant-wide control procedure by Larsson and Skogestad (29), which is considered as a systematic procedure for control structure design for WWTPs (30). The methodology applied in the present study is summarized in Fig.1.

$<$ Figure 1 $>$

In brief, once the goal of the system is set (Step 1), the process is optimized in the second step. Process optimization is done via scenario analysis, which in this study consists of a set of scenario simulations run at different SRT and Qp values in order to find the pair that leads to the highest phosphorus recovery at the optimal N-to-P ratio for downstream algal cultivation (9). In Step 3, the controlled (CVs) and manipulated variables (MVs) are identified through a degree of freedom analysis. Once identified, the pairing of MVs with CVs is done based on the relative gain array (RGA, [32]). Then, in Step 4, all controllers are modelled as PI controllers (Eq. 1), unless otherwise specified. All controllers are tuned following the internal model control (IMC) rules, whereby the controller gain $\left(\mathrm{K}_{\mathrm{c}}\right)$ and the integral time $\left(\tau_{\mathrm{I}}\right)$ are obtained (Eq. 1, [32]). The equation from the IMC rules is chosen based on the order of the transfer function model. Transfer functions are obtained by introducing a step change on each MV and recording the dynamic response, to which a first order model is fitted. The desired closed-loop time constant $\left(\tau_{\mathrm{C}}\right)$ is chosen as the process time constant $\left(\tau_{\mathrm{P}}\right)$, unless otherwise specified. In all cases $\tau_{\mathrm{C}}$ has been chosen following the guidelines by Skogestad (33).

$u(t)=\bar{u}+K_{c} \cdot e(t)+\int_{0}^{t} \frac{K_{c}}{\tau_{I}} \cdot e(t)$

However, if the transfer function needed for the tuning cannot be obtained (e.g. controllers that work during the batch) the controller is manually tuned. The evaluation is divided in two steps. First, the system is subjected to step disturbances in the influent quality, whereby one factor is changed at a time to gain insights on the impact of each factor on the EBP2R performance (Step 5). The step change magnitude was set based on literature as $\pm 20 \%$ for TCOD, $\pm 30 \%$ for TN and $\pm 20 \%$ for TP (23). The steps are each time introduced on day 50 of a 100 days simulation. Thereby, it is demonstrated that the system has reached steady state conditions before the step change is introduced. In case the control system failed in keeping the system stable after the introduction of a step disturbance, $\tau_{\mathrm{C}}$ was tuned again (i.e. back to Step 4). Secondly (Step 6), to assess the process performance under more realistic conditions, a dynamic influent time series is adapted from the BSM1 (27). The influent includes 14 days variations in the influent TCOD, TN, TP and flow rate (Fig. S2). For comparison purposes, the phosphorus recovered and the N-to-P ratio are chosen as performance indicators. In terms of process controllability, the variability of the N-to-P ratio and the time the $\mathrm{N}$-to-P ratio is not within the range defined by a threshold value of $\pm 5 \%$ around the optimal value have been used as performance indicators.

\section{RESULTS}

Step 1, the goal definition, is common for both configurations (CFS/SBR). The overall goal of the TRENS system is to produce an algal suspension encapsulating nutrients in slow-leaching form (i.e. 
algal biomass) and poor in soluble inorganic nutrients - a medium aimed to be used for fertigation (11). The effluent produced by the TRENS system should be harmless to the environment. To avoid soil pollution and eutrophication of ground water due to infiltration as a consequence of fertigation, the primary goal for the EBP2R is to keep the N-to-P ratio in the PBR influent at the optimal value for the algal species that are cultivated. For our case study, the N-to-P ratio considered is 17 , expressed on molar basis, which is optimal for the algal consortium reported by Wágner et al. (34). If the effluent N-to-P ratio is sub-optimal, the bulk of the nutrients cannot be taken up via algal storage and growth, thereby compromising the effluent quality of the PBR. The secondary goal of the system is to maximize resource recovery. To this end, the phosphorus recovery, conventionally produced from a non-renewable resource (35), should be maximized. In case the maximum phosphorus recovery leads to a relatively high N-to-P ratio, part of the nitrogen should be removed via CANR. On the other hand, if the maximum phosphorus recovery leads to N-to-P ratios lower than 17, less phosphorus should be recovered via P-stream diversion. Therefore, the maximized nutrient recovery does not compromise the end use of the treated wastewater via fertigation. The next step in the plant-wide procedure is to optimize the process according to the defined goals, which depend on the system configuration (i.e. SBR or CFS).

\subsection{CONTINUOUS FLOW CONFIGURATION}

\subsubsection{Process optimization}

In Step 2, the process operation for the CFS is optimized and results are shown in Fig. 2. When the SRT is lower than $3.5 \mathrm{~d}$ the phosphorus recovery is limited due to the wash-out of the PAOs. Depending on the P-stream flow rate $\left(\mathrm{Q}_{\mathrm{P}}\right)$, at SRTs higher than $4.5 \mathrm{~d}$ conditions may support nitrifying bacterial growth, thereby oxidizing ammonia to nitrate. The presence of nitrate in the anaerobic phase promotes denitrification, whereby the available COD is oxidized rather than stored by PAOs. Since PAOs cannot take up sufficient VFAs under these conditions, their growth is limited along the aerobic phase, thus leading to their wash-out from the reactor. At high $\mathrm{Q}_{\mathrm{P}}$, PAOs growth is limited due to phosphorus starvation in the aerobic reactor. Considering maximum phosphorus recovery, the effluent N-to-P ratio would be 18 (Qp as 40\% of the influent flow rate and SRT of 4.5 d, Fig.2). Therefore, the operation of the CFS is limited by phosphorus and part of the $\mathrm{N}$-stream should be diverted to a CANR system to remove the excess nitrogen content.

The selection of the set points should consider the process constraints. Optimal phosphorus recovery can be achieved at $\mathrm{SRT}=4.5 \mathrm{~d}$ and $\mathrm{Q}_{\mathrm{P}}=40 \%$ of the influent flow rate, thereby recovering about $70 \%$ of the influent phosphorus. However, if the control action requires increasing $Q_{p}$ - to compensate for a phosphorus deficiency - it results in a further decrease in phosphorus recovery. This is because beyond the $40 \%$ diversion the phosphorus recovery decreases at increasing Qp. In this study, we have selected a phosphorus recovery rate of $65 \%$ of the influent phosphorus as target, which corresponds to Qp of 30\% at SRT=4.5 d. The dissolved oxygen (DO) level needs to be controlled to ensure oxygen supply for heterotrophs and PAO growth. The set point chosen for DO is $1.5 \mathrm{mg} \cdot \mathrm{L}^{-1}$, which has been found as a good trade-off to hinder the growth of both filamentous and nitrifying bacteria (9).

$<$ Figure 2> 


\subsubsection{Identification and pairing of CVs and $M V s$}

The CVs are DO level, phosphorus load, SRT and N-to-P ratio. The CFS has three different flow rates that can be used as MVs: $\mathrm{Q}_{\mathrm{p}}$, the wastage flow rate $\left(\mathrm{Q}_{\mathrm{w}}\right)$ and the $\mathrm{N}$-stream flow rate $\left(\mathrm{Q}_{\mathrm{N}}\right)$. All flows are represented as valves in Fig. 3. The paring is done based on the RGA (Table 2), which is based on the plant transfer functions shown in Table 1. We assume that SRT is controlled by $\mathrm{Qw}_{\mathrm{w}}$, in agreement with the optimization done in step 2, and this pair is therefore left out of the RGA. Qp is used to control the phosphorus load conveyed to the PBR. The N-stream is split by a valve, so the valve controls the N-to-P ratio to the PBR by regulating $Q_{N}$. The air supply is modelled via the gas mass transfer coefficient, $\mathrm{k}_{\mathrm{L}}$ a. In the aerobic tank, air supply is used to keep the oxygen level at 1.5 $\mathrm{mg} \cdot \mathrm{L}^{-1}$. Since the mixing is not modelled explicitly it is not considered as a suitable actuator in this study. Fig. 3 shows the resulting control structure (Step 3).

$<$ Table $1>$

$<$ Table $2>$

$<$ Figure $3>$

\subsubsection{Controller tuning}

Step 4 constitutes the control tuning procedure following the IMC rules. The transfer functions used for tuning of the controllers are shown in Table 1, whilst the tuning parameters are included in Table 3. For all cases, $\tau_{\mathrm{C}}$ was set as $\tau_{\mathrm{P}}$, except for the N-to-P ratio, where a more aggressive control action was required.

$<$ Table 3>

\subsubsection{Evaluation with step disturbances in the influent}

Once the controllers are tuned, in Step 5 the control system is tested by imposing influent step disturbances. The negative step changes on the total influent COD do not considerably affect the CVs (Fig. 4a). At decreasing influent COD concentration, the phosphorus load decreases, likely due to the lower phosphorus release in the anaerobic tanks as a consequence of the lower COD available for PHA storage. COD does not affect the nitrogen content in the N-stream and, consequently, the $\mathrm{N}$-to-P ratio increases only up to 18 . The control system effectively rejects the disturbance. Step disturbances in the opposite direction have a symmetric effect (Fig. S3).

\section{$<$ Figure $4>$}

If the negative step change is induced in the influent phosphorus concentration, the phosphorus load decreases. The reason, in part, is the lower phosphorus content to recover from the influent. However, the PAO abundance decreases due to a growth limitation imposed in the aeration tank as a consequence of the phosphorus starvation. Importantly, the control system is constrained in this 
case, because, if the control action requests $Q_{p}$ higher than $40 \%$ of the influent flow rate, the phosphorus load to be recovered will be lower as well (Fig. 2a). Therefore, the control action was constrained with an upper boundary at $\mathrm{QP}_{\mathrm{P}}=40 \%$ to avoid that the controller drives the EBP2R to an operational condition whereby PAOs are washed out of the system. As a consequence, the phosphorus load conveyed to the PBR cannot be kept at the set point. The delay of the phosphorus load decrease with respect to the step change results from the polyphosphate storage by PAOs (i.e. while PAOs still have enough phosphorus stored and can effectively grow in the aerobic phase, the phosphorus load to the PBR can be kept; Fig. 4b). Nevertheless, it should be noted that the recovery would still be close to the optimal conditions in terms of percentage of phosphorus recovered from the influent (62.5\% of the influent phosphorus). Conversely, the N-to-P ratio can be kept at 17, as the extra nitrogen can be diverted to the CANR system for removal. On the other hand, the positive steps in the influent phosphorus load can be effectively rejected by the control system (Fig. S3).

Finally, the system was tested against step changes in the influent nitrogen content. Nitrogen related disturbances did not affect the phosphorus recovery, as nitrifiers were washed out of the reactor at the selected operational conditions. Regarding the N-to-P ratio, the lower the content of nitrogen in the reactor is the lower the N-to-P ratio will be. If the nitrogen content is too low, there would not be sufficient nitrogen to compensate for the phosphorus recovery. A supervisory layer would be needed to overcome this limitation by lowering the set point of the phosphorus load controller under such conditions. On the other hand, positive steps in the nitrogen content could be effectively corrected by the control system by diverting part of the N-stream to the CANR (Fig. S3).

Although the proposed control system performed well in terms of phosphorus recovery and N-to-P ratio fed to the PBR, the DO controller failed keeping the optimal oxygen level. Therefore, $\tau_{C}$ was decreased until a maximum offset of $0.15 \mathrm{mg} \mathrm{L}^{-1}$ was achieved.

\subsubsection{Evaluation with the BSM1 dynamic influent}

Finally, the system is simulated under dynamic conditions (Step 6). Fig. 5a shows that the control system is able to smooth the variations in the P-load, only allowing very small deviations from the set point. However, the N-to-P ratio shows some variability (average N-to-P ratio $16.45 \pm 2.48$, Fig. $5 b)$. When the influent nitrogen into the treatment plant is too low, the control system is not able to keep the set point and the N-to-P ratio falls under the optimal value. Nevertheless, the variability of the effluent N-to-P ratio when control is applied is considerably lower than in the open-loop case, i.e. the case where the system is not controlled. The variability in the actuators is shown in Fig. S4.

$<$ Figure 5>

\subsection{SEQUENCING BATCH CONFIGURATION}

\subsubsection{Process optimization}

Similar to the CFS, the SBR is optimized through scenario simulations, which are shown in Fig.6 (Step 2). At SRT<3.5 d, PAOs are washed out from the reactor, thereby leading to a poor control of phosphorus recovery. At SRT ranging from 5 to $6 \mathrm{~d}$, PAOs activity is limited by nitrification. Nitrifiers oxidize ammonia to nitrate, which then becomes available in the anaerobic phase for denitrification. Nitrate can hinder the VFA uptake by PAOs during the anaerobic phase, leading to 
their wash-out. Higher SRT supports both nitrification and phosphorus removal. However, ammonia is in that case removed via nitrification-denitrification, limiting the nitrogen availability for downstream algal cultivation. Therefore, it can be concluded that the optimal operation ranges between 3.5 and $5 \mathrm{~d}$ SRT, where the maximum recovery is reached around SRT equal to $4.5 \mathrm{~d}$.

The difference between Fig. 2a and 6a is noteworthy. Whilst the potential phosphorus recovery is limited by starvation at high $Q_{P}$ in the CFS, in the SBR, PAOs grow at any Qp. Since the SBR induces concentration gradients, at the beginning of the aerobic phase there is always a comparably higher phosphate concentration to support PAOs growth. However, in the CFS, this is not the case, and PAOs are constantly exposed to low phosphate concentrations. At high Qp the phosphorus level in the aerobic reactor of the CFS may be too low to support PAO growth. Additionally, at high Qp the solids become more concentrated in the aeration tank of the CFS, thereby increasing the aerobic SRT. High aerobic SRTs can support the growth of nitrifying bacteria with the consequent nitrate recycle to the anaerobic phase, which deteriorates the EBP2R performance.

Since the phosphorus recovery is not limited by phosphorus starvation in the aerobic phase one could choose the highest Qp. However, the SBR is limited by the influent nitrogen. An N-to-P ratio of 17 can be achieved by just diverting $28 \%$ of the influent flow rate as Qp at the optimal SRT of $4.5 \mathrm{~d}$. A higher phosphorus recovery rate would lead to a nitrogen imbalance that could only be corrected by adding an external nitrogen source into the EBP2R effluent.

$<$ Figure 6>

\subsubsection{Identification and pairing of CVs and $M V s$}

As for the CFS, there are up to four candidates for CVs. The phosphorus load and the SRT should be controlled to keep the maximum phosphorus recovery. The available actuators are the effluent pump and the oxygen supply, modelled through the $\mathrm{k}_{\mathrm{L}} \mathrm{a}$. Additionally, each of the actuators can be active at different times along the SBR cycle, meaning that the same actuator can be used for more than one control purpose if they are not coincident in time. Finally, the N-stream can be split by a valve in two different streams, one feeding the PBR and a second one feeding the CANR system.

Two different control structures are proposed (Step 3) - Fig. 7. Based on Fig. 6, the N-to-P ratio can be controlled at 17 by manipulating Qp (i.e. using the effluent pump at the end of the anaerobic phase), proposed as control structure 1 (CS-1). Since the system is limited by the nitrogen content in wastewater, such a control structure will always drive the process to the maximum phosphorus recovery without compromising the $\mathrm{N}$-to-P ratio. To keep the optimal N-to-P ratio, the corresponding MV, Qp, should be kept at 34\% diversion of the influent flow rate. A second option (CS-2) is to uncouple the phosphorus recovery from the N-to-P ratio, where the first one is controlled by Qp and the second one by using the valve, splitting the flow between the PBR and the CANR (similar to the pairing given by the RGA for the CFS). The set point for the phosphorus load is set at $125 \mathrm{~kg} \mathrm{P} \cdot \mathrm{d}^{-1}$, which leads to decoupling the control of the phosphorus recovery from the control of the N-to-P ratio at relatively high phosphorus recovery rate $(72 \%$ of the influent 
phosphorus load). The SRT and the DO level control schemes are the same for CS-1 and CS-2. The set point for the SRT controller is set based on Fig. 6 (SRT=4.5 d), which is controlled by pumping the wastage of activated sludge at the end of the second settling phase. The DO level is controlled by manipulating the $\mathrm{k}_{\mathrm{L}} \mathrm{a}$ in both cases. As the oxygen is supplied along the aerobic reaction phase, the control action should take place during the batch. The DO is set at $1.5 \mathrm{mg} \cdot \mathrm{L}^{-1}$ in both cases (9).

$<$ Figure 7 $>$

\subsubsection{Controller tuning}

Controllers are tuned according to the IMC rules (Step 4). The transfer functions of the plant, needed for the tuning, are shown in Table 4 . For all cases $\tau_{\mathrm{C}}$ was set as $\tau_{\mathrm{P}}$ as a first tuning approach. In the CS-1, this led to a too aggressive controller, which led to oscillations in the process performance around the desirable set point, and the tuning parameters were corrected accordingly by relaxing $\tau_{\mathrm{C}}$. On the contrary, the CS-2 control action was too mild and the controller was unable to reach the set point. Therefore, the controller was tuned more aggressively by decreasing $\tau_{C}$. Since the oxygen controller works during the cycle a transfer function at steady state cannot be obtained. Therefore, this controller was manually tuned. For simplicity, the DO controller was tuned as a proportional controller. Final tuning parameters are shown in Table 5.

$<$ Table 4>

$<$ Table 5>

\subsubsection{Evaluation with step disturbances in the influent}

To identify the best control strategy, both CS-1 and CS-2 are compared against step disturbances in the influent to the SBR (Step 5). Both the influent step in nitrogen and phosphorus upset the system by pushing the effluent N-to-P ratio away from the optimal value (Fig. 8). Interestingly, CS-1 shows higher variability than CS-2 in the N-to-P ratio fed to the PBR.

$<$ Figure 8 $>$

The oscillations in the control action are a consequence of the discontinuous nature of the SBR operation. The controller can only act up to four times per day (a number corresponding to the number of daily SBR cycles), which makes it difficult to effectively reject disturbances.

Furthermore, the controller aims to reject the nutrient load in the short term. However, especially in case of the phosphorus step change, the controller has to also compensate for the comparably slow dynamics of biological reaction rates. The PAOs increase the phosphorus release in the anaerobic phase, thereby amplifying the impact of the disturbance and extending the dynamic change for some more days (e.g. Fig. 8b shows comparably high oscillations around day 60). Results obtained indicate that CS-1 can induce oscillations on the phosphorus load, similar to those induced by CS-2 (Fig. 9a), because it was not controlled and followed the trends imposed by the control action to 
correct the N-to-P ratio. When CS-1 is implemented, the high interaction between phosphorus load and N-to-P ratio prevents the SBR from keeping the optimal N-to-P ratio in the effluent. However, CS-2 can effectively maintain the effluent N-to-P ratio and thus is further assessed (Fig. 9). The impact of the TCOD was negligible and no discrimination between CS-1 and CS-2 could be made based on the data obtained (not shown).

Profiles in Fig. 9 reveal that oscillations appear in the phosphorus load for CS-2, again due to the discontinuous nature of the process. Despite the variability of the phosphorus load, the controller can maintain the optimal effluent N-to-P ratio in the EBP2R effluent. Although CS-2 seems to be a more complex option (it requires two control actions), it decouples the control of phosphorus load and N-to-P ratio. Therefore, the N-to-P ratio controller, relying on an in-cycle ammonia measurement, can effectively compensate for the interactions between the phosphorus load and $\mathrm{N}$ to-P ratio. Simulation results for positive step changes are shown in Fig. S5.

$<$ Figure 9>

\subsubsection{Evaluation with the BSM1 dynamic influent}

Finally, the performance of CS-2 is further analysed in a more realistic scenario, based on the BSM1 (Step 6). To test this scenario a retention tank is included in the layout. The retention tank acts already as a buffer, thereby smoothing the impact of the disturbances (Fig. S7). Despite the buffering effect, the dynamic influent can significantly affect the system performance (see Fig. 10). The controller suffers again from oscillations, especially due to a peak in the phosphorus load during the first day of simulation (Fig. 10a). The overcompensation of the controller suggests that it has been tuned too aggressively. However, the system stabilizes along the simulation period, effectively smoothing the phosphorus load. Similarly, the control action variability reduces towards the end of the simulation period (Fig. S6). The tuning of the phosphorus load controller is therefore a critical step in the design of an optimal control structure for the SBR configuration. With regard to the N-to-P ratio (Fig. 10b), the control system can effectively maintain the effluent quality (average $\mathrm{N}$-to-P ratio is $16.9 \pm 0.07)$.

$<$ Figure 10 $>$

\section{DISCUSSION}

This work presents the control system for an EBP2R system implemented in two different configurations. When developing the control structure, different challenges have been faced. Based on the optimization carried out in Fig. 2 and Fig. 6, it was concluded that the SBR leads to a higher

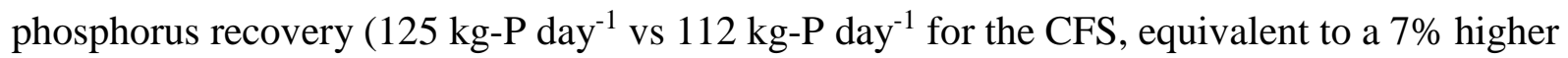
phosphorus recovery from the influent for the SBR). PAOs are less sensitive to $Q_{p}$ in the SBR because there is sufficient phosphorus to support their growth under aerobic conditions, thereby leading to higher phosphorus recovery rates compared to the CFS. The estimated phosphorus recovery is in the range of similar systems tested in both laboratory scale or modelling studies (3638). The SBR was found to be more sensitive to influent disturbances, showing a high variability 
on the recovered phosphorus even when a single influent property was disturbed. On the contrary, the N-to-P ratio was rather stable $(16.9 \pm 0.07)$ and never exceeding $\pm 5 \%$ of the optimal N-to-P ratio boundaries. The tuning of the phosphorus load controller is therefore a critical step when developing a control structure for the sequencing batch reactor scheme. On the other hand, the CFS stabilized better the phosphorus load under dynamic conditions (Fig. 5a). However, the effluent quality was compromised in this system, showing larger deviations from the optimal N-to-P ratio (average effluent $\mathrm{N}$-to-P ratio $16.45 \pm 2.48$ ). For $40 \%$ of the simulated time the N-to-P ratio exceeded $\pm 5 \%$ of the optimal value, thus showing comparably worse controllability than the SBR. Interestingly, none of the systems required the addition of any chemical to facilitate their control, which is the consequence of the dedicated optimization of the microbial community (Fig. 2 and Fig. 6), as suggested by Yuan et al. (15). Therefore, the designed control system does not compromise the sustainability of the process, as has happened in cases where metal dosing was used to control phosphorus removal (39).

Traditionally, the optimal N-to-P ratio for a given algal species was considered to be a constant value (40). However, there is some evidence suggesting that the optimal N-to-P ratio is a range rather than a specific value. As example, algae can store both nitrogen and phosphorus, which they can use to support their growth when one of them becomes limiting in the medium $(6,41)$. Furthermore, the uptake rates and storage may be affected by the culture history and may be increased after starvation (34). For mixed cultures grown under varying influent conditions, the Nto-P ratio may promote growth of one algae species over the others, which can further adapt their nutrient content depending on the cultivation medium (42). The combination of these factors suggests that the algae would be able to take up and store all the incoming nutrients, even if there is some imbalance between them. Further research should address to what extent the N-to-P ratio can be varied from the optimal value without significantly compromising the PBR effluent quality. Importantly, the N-to-P ratio is a valuable tool to control the algal populations and it could be used not only for optimal nutrient recovery, but also to maintain the desired algal species in the PBR (43). Therefore, the impact of the N-to-P influent variability on the culture dynamics should be also assessed in the future.

Finally, it should be noted that, despite the fact that this study focuses on algal cultivation, the developed control strategies can be further applied to other resource recovery technologies. A good example is the BCFS process, whereby a P-stream is diverted from the anaerobic tank of an EBPR system for phosphorus recovery via struvite precipitation (36). The control structures presented by Barat and van Loosdrecht (36) are comparably simpler than the control system we propose.

However, our control strategy allows a better management of the phosphorus in the aerobic phase, thereby minimizing the risk of PAOs wash-out due to phosphorus starvation. The optimization exercise shown in Fig. 2 and Fig. 6 is also relevant to other resource recovery technology schemes based on short SRT EBPR systems (e.g. 44), whereby phosphorus recovery can be combined with biogas production via anaerobic digestion.

The results reported in this study should be interpreted with care. ASM2d has been selected for this study, as it is a model commonly used for EBPR systems (45). However, ASM2d does not account for the differences between microbial communities grown in continuous and sequencing batch 
reactors (46). Since the SBR induces substrate gradients to the bacteria and in the continuous system the bacteria are mostly exposed to low substrate concentrations, the microbial diversity in SBR and CFS is expected to be different. This is especially relevant, for instance, to control filamentous bulking in EBPR systems, where the SBR configuration was found less prone to excessive growth of filamentous bacteria that could upset the process (47). Furthermore, the modelbased optimization may induce changes in the reactor microbial communities that the ASM2d does not consider, leading to falsification issues (48). A model accounting also for the potential risk of suffering filamentous bulking (e.g. 49) could be more suitable for process design, control and optimization for an EBP2R system. Consequently, the control systems should be tested in laboratory-scale prior to full scale implementation.

\section{CONCLUSIONS}

In this study two different configurations of the EBP2R system are critically compared through a control structure design for optimal phosphorus recovery. Based on our results we conclude that:

- The SBR allows for higher phosphorus recovery via P-stream diversion, recovering up to $125 \mathrm{~kg}-\mathrm{P} \mathrm{d}^{-1}$ (72\% of the influent phosphorus load), while the continuous system only recovers $112 \mathrm{~kg}-\mathrm{P} \mathrm{d}^{-1}$ (65\% of the influent phosphorus load).

- Two different control structures were tested to control the SBR (CS-1/CS-2). The EBP2R performs better when the control of the phosphorus load is uncoupled from the control of the $\mathrm{N}$-to-P ratio. CS-2 effectively keeps the optimal N-to-P ratio in the effluent (16.9 \pm 0.07$)$. However, the system is very sensitive to the influent disturbances and the tuning of the phosphorus load controller has been identified as a critical step in the control structure design.

- One control structure is tested in the CFS. The proposed control structure is able to keep a fairly constant phosphorus load. However, the N-to-P ratio shows high variability under dynamic conditions (16.45 \pm 2.48$)$. The main challenge when designing the control structure is to keep the system away from saturation conditions, which imposes constraints to the control action.

- In both cases the dosing of chemicals, which is widely used to control nutrient removal in WWTPs, has been avoided through careful microbial management. Therefore, an important conclusion is that the system can be controlled without compromising the sustainability of the process.

Overall, results suggest that the SBR outperforms the continuous system, both in terms of nutrient balance fed to the PBR and phosphorus recovery. However, given the sensitivity of the control structures towards the influent dynamics, it may be better to implement continuous EBP2R systems in those treatment plants expected to be subjected to large variations. Furthermore, although the CFS leads to lower phosphorus recovery than the SBR, the performance is still better compared to other available technologies (e.g. [37]).

\section{ACKNOWLEDGEMENTS}


Borja Valverde-Pérez thanks the Integrated Water Technology (InWaTech) project (http://www.inwatech.org.www6.sitecore.dtu.dk/) for the financial support.

\section{REFERENCES}

[1] J.A. Foley, N. Ramankutty, K.A. Brauman, E.S. Cassidy, J.S. Gerber, M. Johnston, N.D. Mueller, C. O’Connell, D.K. Ray, P.C. West, C. Balzer, E.M. Bennett, S.R. Carpenter, J. Hill, C. Monfreda, S. Polansky, J. Rockström, J. Sheehan, S. Siebert, D. Tilman, D.P.M. Zaks. Solutions for a cultivated planet. Nature, 478 (2011), 337-342.

[2] A.R. Sheik, E.E.L. Muller, P. Wilmes. A hundred years of activated sludge: time for a rethink. Frontiers in Microbiology, 47(5) (2014), 1-7.

[3] W. Verstraete, P. Van de Caveye, V. Diamantis. Maximum use of resources present in domestic used water. Bioresource Technology, 100 (2009), 5537-5545.

[4] L.E. De Bashan, Y., Bashan. Recent advances in removing phosphorus from wastewater and its future use as fertilizer (1997-2003). Water Research, 8 (2004), 4222-4246.

[5] S. Matassa, D.J., Batstone, T., Hülsen, J., Schnoor, W., Verstraete. Can direct conversion of used nitrogen to new feed and protein help feed the world? Environmental Science and Technology, 49 (2015), 5247-5254.

[6] A.N. Shilton, N., Powell, B., Guieysse. Plant based phosphorus recovery from wastewater via algae and macrophytes. Current Opinion in Biotechnology, 23 (2012), 884-889.

[7] J. Coppens, O. Grunert, S. Van Den Hende, I., Vanhoutte, N. Boon, G. Haesaert, L. De Gelder. The use of microalgae as a high-value organic slow-release fertilizer results in tomatoes with increased carotenoid and sugar levels. Journal of Applied Phycology (2016), In press.

[8] A. Solovchenko, A.M. Verschoor, N.D. Jablonowski, L.Nedbal. Phosphorus from wastewater to crops: an alternative path involving microalgae. Biotechnology Advances, (2016), In press.

[9] B. Valverde-Pérez, E., Ramin, B.F., Smets, B.Gy., Plósz. EBP2R - An innovative enhanced biological nutrient recovery activated sludge system to produce growth medium for green microalgae cultivation. Water Research, 68 (2015), 821-830.

[10] T. Cai, S.Y., Park, Y., Li,. Nutrient recovery from wastewater streams by microalgae: status and prospects. Renewable Sustainable Energy Reviews, 19 (2013), 360-369.

[11] L.L. Fang, B., Valverde-Pérez, A., Damgaard, B. Gy., Plósz, M., Rygaard. Life cycle assessment as development and decision support tool for wastewater resource recovery technology. Water Research, 88 (2016), 538-549.

[12] G. Olsson. ICA and me - A subjective review. Water Research, 46 (2012), 1585-1624.

[13] X. Flores-Alsina, A., Gallego, G., Feijoo, I., Rodríguez-Roda. Multiple-objective evaluation of wastewater treatment plant control alternatives. Journal of Environmental Mangement, 91 (2010), 1993-1201. 
[14] J. Guerrero, A., Guisasola, J., Comas, I., Rodríguez-Roda, J.A., Baeza. Multi-criteria selection of optimum WWTP control set points based on microbiology-related failures, effluent quality and operating costs. Chemical Engineering Journal, 188 (2012), 23-29.

[15] Z. Yuan, A., Oehmen, Y., Peng, Y., Ma, J., Keller. Sludge population optimization in biological nutrient removal wastewater treatment systems through on-line process control: a review. Reviews in Environmental Science and Biotechnology, 7 (2008), 243-254.

[16] F. Grognard, A.R., Akhmetzhanov, O., Bernard. Optimal strategies for biomass productivity maximization in a photobioreactor using natural light. Automatica, 50 (2014), 359-368.

[17] G. Olivieri, P., Salatino, A., Marzocchella. Advances in photobioreactors for intensive microalgal production: configurations, operating strategies and applications. Journal of Chemical Technology and Biotechnology, 84 (2014), 178-195.

[18] L. Wang, M., Min, Y., Li, P., Chen, Y., Chen, Y., Liu, Y., Wang, R. Ruan. Cultivation of green algae Chlorella sp. in different wastewaters from municipal wastewater treatment plant. Applied Biochemistry and Biotechnology, 162 (2010), 1174-1186.

[19] J.K. Huusom. Challenges and opportunities in integration of design and control. Computers and Chemical Engineering, 81 (2015), 138-146.

[20] B. Valverde-Pérez, J.M., Fuentes-Martínez, X., Flores-Alsina, K.V., Gernaey, J.K., Huusom, B.Gy., Plósz. Control structure design of an innovative enhanced biological nutrient recovery activated sludge system coupled with a photobioreactor. Computer Aided Chemical Engineering, 37 (2015), 2555 - 2560.

[21] J.P. Steyer, O., Bernard, D.J., Batstone, I., Angelidaki. Lessons learnt from 15 years of ICA in anaerobic digesters. Water Science and Technology, 53(4-5) (2006), 25-33.

[22] M. Mauricio-Iglesias, A.K., Vangsgaard, K.V., Gernaey, B.F., Smets, G., Sin. A novel control strategy for single-stage autotrophic nitrogen removal in SBR. Chemical Engineering Journal, 260 (2015), 64-73.

[23] G. Tchobanoglous, F., Burton, H., Stensel, 2004. Wastewater Engineering: Treatment and Reuse, 4th ed. Metcalf and Eddy. McGraw-Hill Science, New York, USA.

[24] R.J. Zeng, R., Lemaire, Z., Yuan, J., Keller. Simultaneous nitrification, denitrification, and phosphorus removal in lab-scale sequencing batch reactor. Biotechnology and Bioengineering, 84(2) (2003), 170-178.

[25] C.W. Randall, J.L., Barnard, H.D., Stensel, H.D., 1998. Design and retrofit of wastewater treatment plants for biological nutrient removal. Water Quality Management Library 5.

[26] M. Henze, W., Gujer, T., Mino, T., Matsuo, M.C., Wentzel, G.V.R., Marais, M.C.M., Van Loosdrecht. Activated sludge model no 2d, ASM2d. Water Science and Technology, 39 (1999), 165-182. 
[27] X. Flores-Alsina, K.V., Gernaey, U. Jeppsson. Benchmarking biological nutrient removal in wastewater treatment plants: influence of mathematical model assumptions. Water Science and Technology, 65(8) (2012), 1496-1505.

[28] M.N. Pons, M., Casellas, C., Dagot, 2004. Definition of a benchmark protocol for sequencing batch reactors. IFAC Symposium Computer Applications in Biotechnology, CAB9, Nancy, France.

[29] T. Larsson, S., Skogestad. Plantwide control- A review and a new design procedure. Modeling, Identification and Control, 21(4) (2000), 209-240.

[30] A.C.B. Araújo, S., Gallani, M., Mulas, G., Olsson. Systematic approach to the design of operation and control policies in activated sludge systems. Industrial and Engineering Chemistry Research, 50 (2011), 8542-8557.

[31] B. Valverde-Pérez, M., Mauricio-Iglesias, G., Sin, 2015. Systematic design of optimal control system for the SHARON-Anammox process. Journal of Process Control, 39 (2016), 1-10.

[32] D.E. Seborg, T.F., Edgar, D.A., Mellichamp, 2004. Process Dynamics and Control. Second ed., John Wiley and Sons Inc.

[33] S. Skogestad. Simple analytic rules for model reduction and PID controller tuning. Journal of Process Control, 13 (2003), 291-309.

[34] D.S. Wágner, B., Valverde-Pérez, M., Sæbø, M., Bregua de la Sotilla, J., Van Wagenen, B.F., Smets, B.Gy., Plósz, 2015. Towards a consensus microalgal growth model (ASM-A) - uptake and storage of nutrients. Submitted.

[35] D. Cordell, J.O., Drangert, S., White. The story of phosphorus: global food security and food for thught. Global Environmental Change, 19 (2009), 292-305.

[36] R. Barat, M.C.M., van Loosdrecht. Potential phosphorus recovery in a WWTP with the BCFS process: interactions with the biological process. Water Research, 40 (2006), 3507-3516.

[37] P.Y., Wong, K.Y., Cheng, A.H., Kaksonen, D.C., Sutton, P., Ginige. A novel post denitrification configuration for phosphorus recovery using polyphosphate accumulating organisms. Water Research, 47(17) (2013), 6488-6495.

[38] B. Acevedo, C. Camiña, J.E. Corona, L. Borrás, R. Barat. The metabolic versatility of PAOs as an opportunity to obtain a highly P-enriched stream for further P-recovery. Chemical engineering Journal, 270 (2015), 459-467.

[39] L. Corominas, H.F., Larse, X., Flores-Alsina, P.A., Vanrolleghem. Including life cycle assessment for decision-making in controlling wastewater nutrient removal systems. Journal of Environmental Management, 128 (2013), 759-767.

[40] G.Y. Ree, I.J., Gotham. Optimum, N:P ratios and coexistence of planktonic algae. Journal of Phycology, 16 (1980), 486-489. 
[41] J. Coppens, B., Decostere, S., Van Hulle, I., Nopens, S.E., Vlaeminck, L., De Gelder, N., Boon. Kinetic exploration of nitrate-accumulating microalgae for nutrient recovery. Applied Microbiology and Biotechnology, 98 (19) (2014), 8377-8387.

[42] A. Beuckles, E., Smolders, K., Muylaert. Nitrogen availability influences phosphorus removal in microalgae-based wastewater treatment. Water Research, 77 (2015), 98-106.

[43] A. Richmond 2004. Handbook of microalgal culture biotechnology and applied phycology. Blackwell Publishing: Oxford.

[44] H. Ge, D.J., Batstone, J., Keller. Biological phosphorus removal from abattoir wastewater at very short sludge ages mediated by novel PAO clade Comamonadaceae. Water Research, 69 (2015), 173-182.

[45] K.Gernaey, M.C.M. van Loosdrecht, M. Henze, L. Morten, S.B. Jørgensen. Activated sludge wastewater treatment plant modelling and simulation: state of the art. Environmental Modelling and Software, 19(9) (2004), 763-783.

[46] J. Wanner. Comparison of biocenoses from continuous and sequencing batch reactors. Water Science and Technology, 25(6) (1992), 239-249.

[47] B. Valverde-Pérez, 2015. Wastewater resource recovery via the Enhanced Biological Phosphorus Removal and Recovery (EBP2R) process coupled with green microalgae cultivation. PhD thesis, Technical University of Denmark, Kgs. Lyngby, Denmark.

[48] G. Sin, K., Villez, P.A., Vanrolleghem. Application of a model-based optimization methodology for nutrient removing SBRs leads to falsification of the model. Water Science and Technology, 53(4-5) (2006), 95-103.

[49] X. Flores-Alsina, J., Comas, I., Rodríguez-Roda, K.V., Gernaey, C., Rosen. Including the effects of filamentous bulking sludge during the simulation of wastewater treatment plants using a risk assessment model. Water Research, 43 (2009), 4527-4538. 
Tables:

Table 1: Plant transfer functions for the continuous flow EBP2R:

\begin{tabular}{|c|c|c|c|c|}
\hline MV/CV & DO & PLOAD $_{\text {N-to-P ratio }}$ & SRT \\
\hline $\mathbf{k}_{\mathbf{L a}}$ & $\frac{0.0331}{2 s+1}$ & $\frac{-143.0977}{9.47 s+1}$ & $\frac{0.02}{8.49 s+1}$ & $\frac{2.71 \cdot 10^{-5}}{4.35 s+1}$ \\
\hline $\mathbf{Q P}_{\mathbf{P}}$ & $\frac{1.9 \cdot 10^{-4}}{91.565 s+1}$ & $\frac{17.463}{13.946 s+1}$ & $\frac{0.0016 e^{-17.2 s}}{207.83 s+1}$ & $\frac{5 \cdot 10^{-4}}{222.79 s+1)}$ \\
\hline $\mathbf{Q W}$ & $\frac{1.8 \cdot 10^{-3}}{5.3 s+1}$ & $\frac{-207.21}{11.85 s+1}$ & $\frac{6.026}{13.6 s+1}$ & $\frac{-6.6 \cdot 10^{-3}}{2 s+1}$ \\
\hline $\mathbf{Q N}_{\mathbf{N}}$ & 0 & $\frac{4.04 \cdot 10^{3}}{2 s+1}$ & $\frac{9.4003}{2 s+1}$ & 0 \\
\hline
\end{tabular}

Table 2: Relative gain array for the continuous flow EBP2R:

\begin{tabular}{|c|c|c|c|}
\hline & $D O$ & $P_{\text {LOAD }}$ & N-to-P ratio \\
\hline$k_{L a}$ & 0.9507 & 0.0465 & -0.0028 \\
\hline$Q_{P}$ & 0.0493 & 0.9896 & -0.039 \\
\hline$Q_{N}$ & 0 & -0.0302 & 1.0362 \\
\hline
\end{tabular}

Table 3: Tuning parameters for the control system for the continuous TRENS. The SRT controller is tuned as a proportional controller. Kc: controller gain; $\tau_{\mathrm{I}}$ : integral time.

\begin{tabular}{|c|c|c|}
\hline & Kc & $\boldsymbol{\tau}_{\mathbf{I}}$ \\
\hline DO & 190 & 2 \\
\hline PLOAD & 0.06 & 14 \\
\hline N-to-P ratio & 10 & 2 \\
\hline SRT & -152 & 0 \\
\hline
\end{tabular}

Table 4. Transfer functions for the sequencing batch EBP2R:

\begin{tabular}{|c|c|c|}
\hline MV/CV & N-to-P ratio & PLOAD \\
\hline QP & $\frac{-0.0062}{s+1}$ & $\frac{14.695}{0.11 s+1}$ \\
\hline
\end{tabular}

Table 5. PI tuning parameters for the control layers. The DO controller is tuned as proportional controller. Kc: controller gain; $\tau_{\mathrm{I}}$ : integral time.

\begin{tabular}{|c|c|c|}
\hline & Kc & $\boldsymbol{\tau}_{\text {I }}$ \\
\hline DO & 500 & - \\
\hline $\begin{array}{c}\text { N-to-P ratio } \\
\text { (CS- 1) }\end{array}$ & -16 & 1 \\
\hline PLOAD (CS-2) & 5 & 0.11 \\
\hline
\end{tabular}




\section{Figures:}

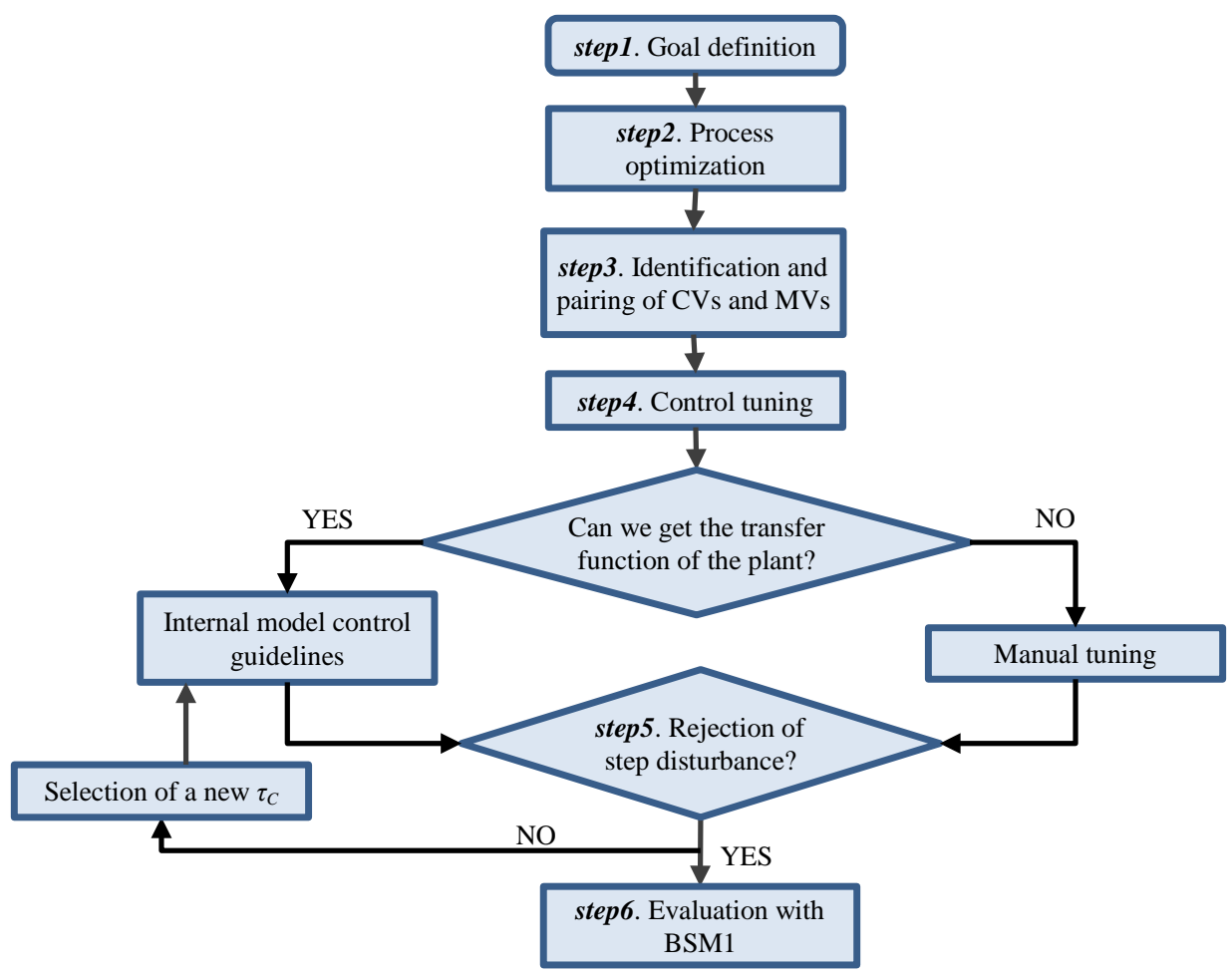

Figure 1 Control structure design methodology (adapted from Valverde-Pérez et al. [31]) 


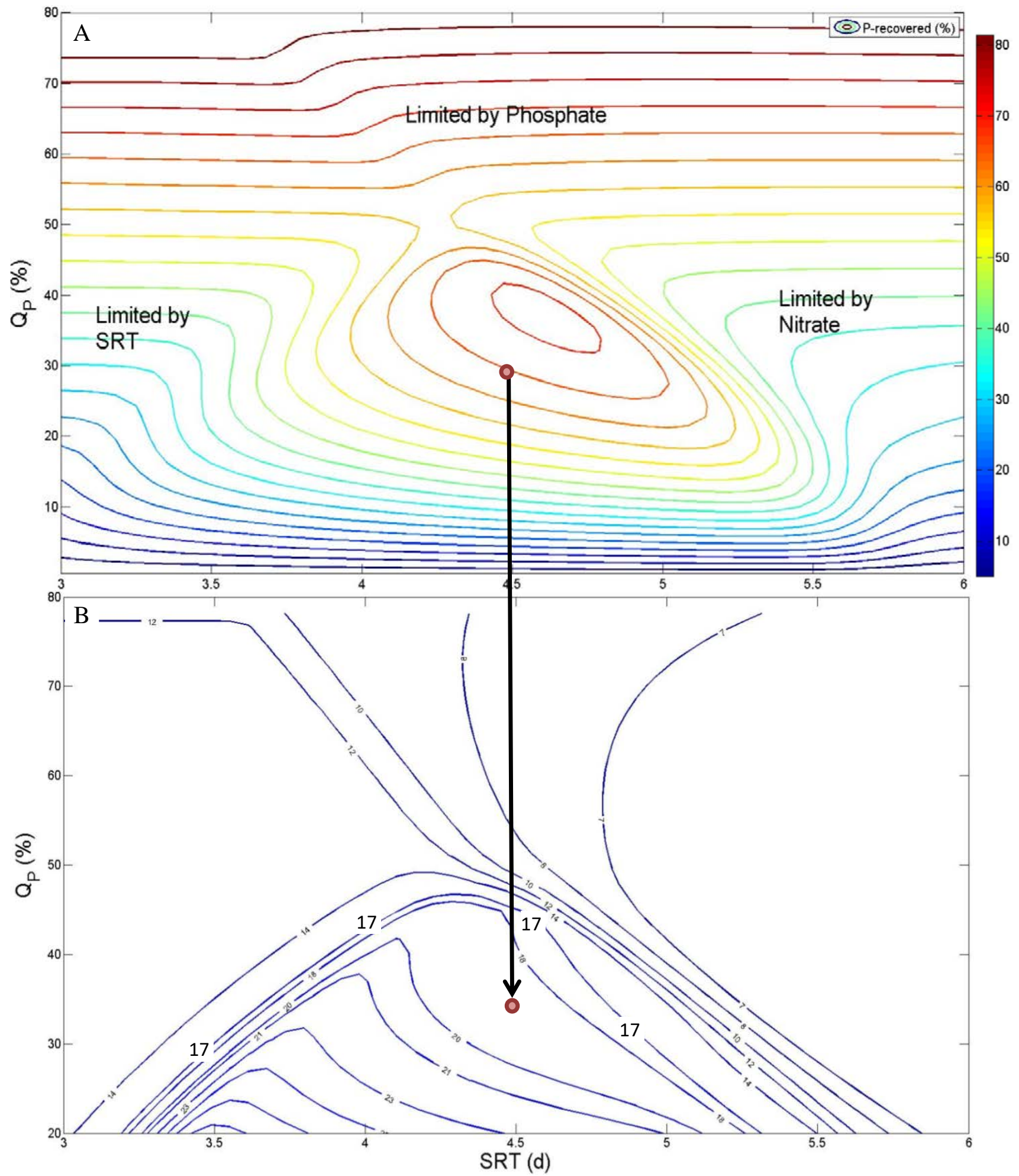

Figure 2 Process performance of the continuous flow EBP2R system: A) Percentage of P recovered from the influent (z-axis) as a function of the P-stream flow (y-axis) and the SRT (x-axis); B) N-to$\mathrm{P}$ molar ratio in the EBP2R effluent (z-axis) as a function of the P-stream flow (y-axis) and the SRT (x-axis). Note that, in our study, the N-to-P ratio of 17 is the optimal nutrient balance for the algae considered to be cultivated downstream of the EBP2R. The red dots represent the selected set points for phosphorus recovery (A) and the N-to-P ratio in the effluent of the EBP2R (B) at the selected Qp. 


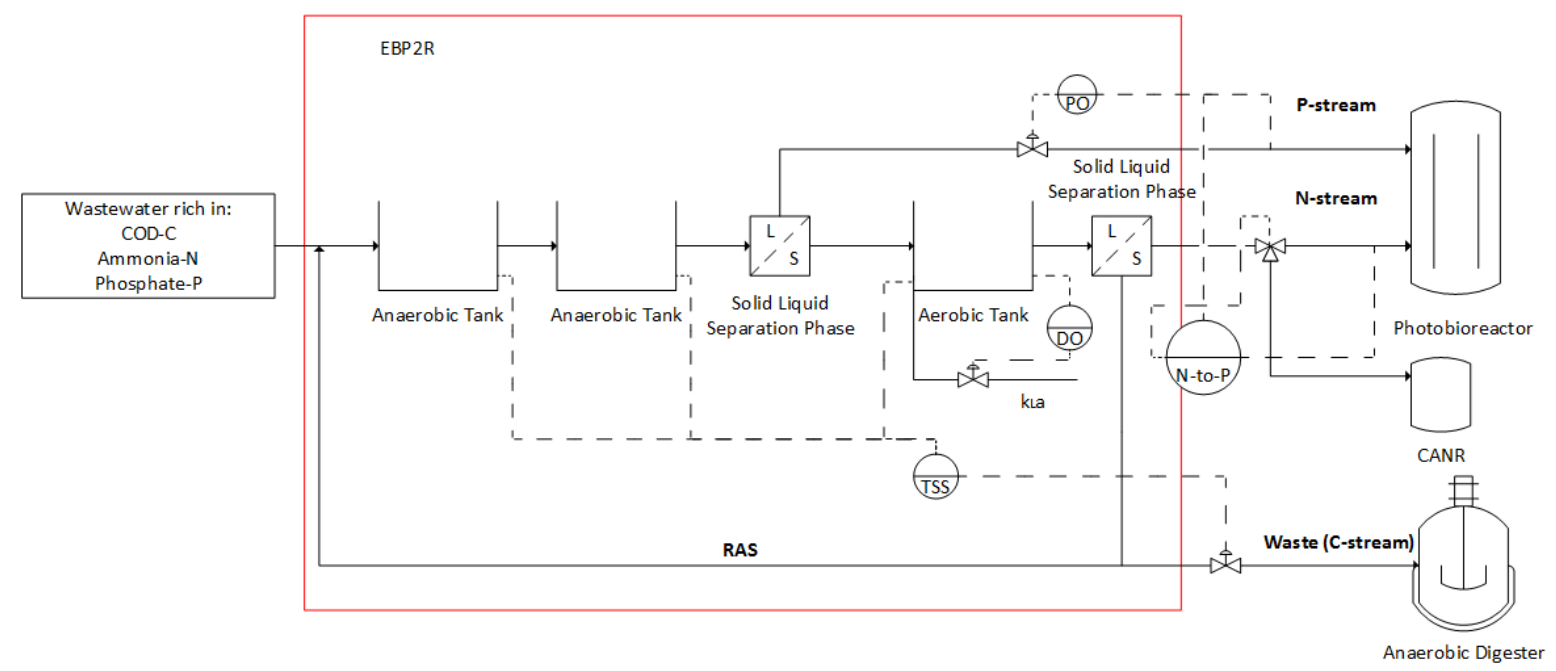

Figure 3 Layout of the control strategy for the continuous flow TRENS. RAS stands for recycle of activated sludge; CANR stands for completely autotrophic nitrogen removal. Controllers are named by the CV they control (e.g. DO is the dissolved oxygen level controller).

A
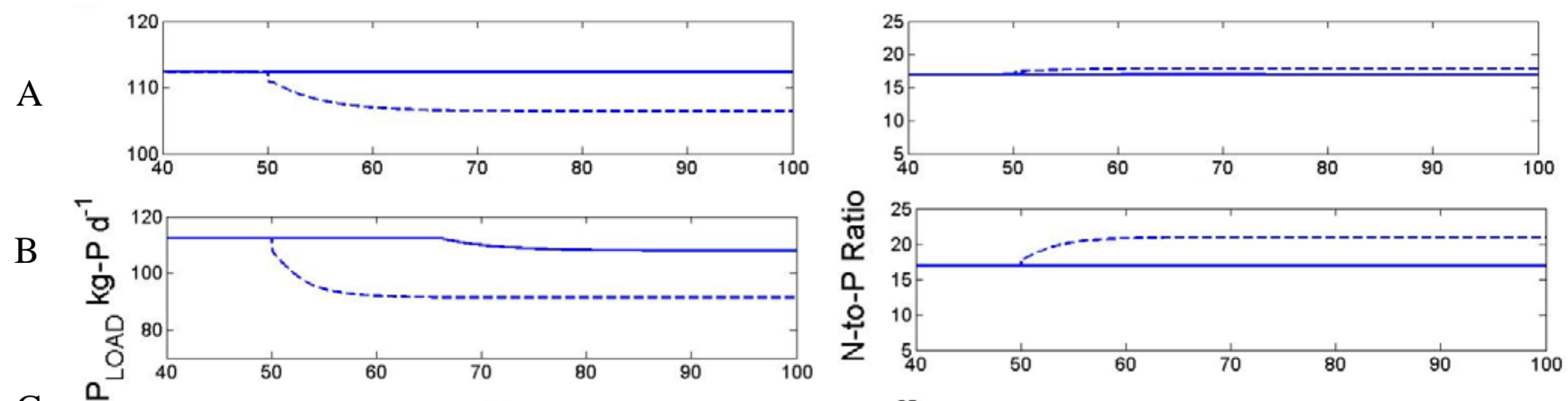

$\mathrm{C}$
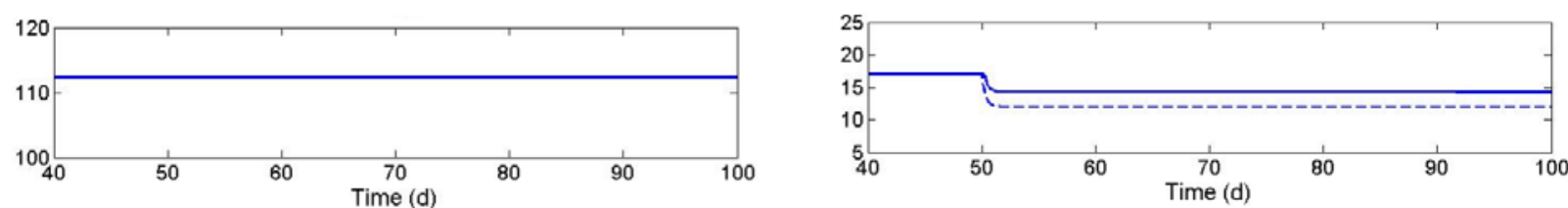

Figure 4 Response of the CFS to step disturbances (step 5): a) Effect of a step change on the influent TCOD of -20\%; b) effect of a step change of -20\% on the influent phosphorus; and c) effect of a step change of $-30 \%$ on the influent ammonia. The full line represents the process response under controlled conditions and the dashed line the process response without control (open-loop).
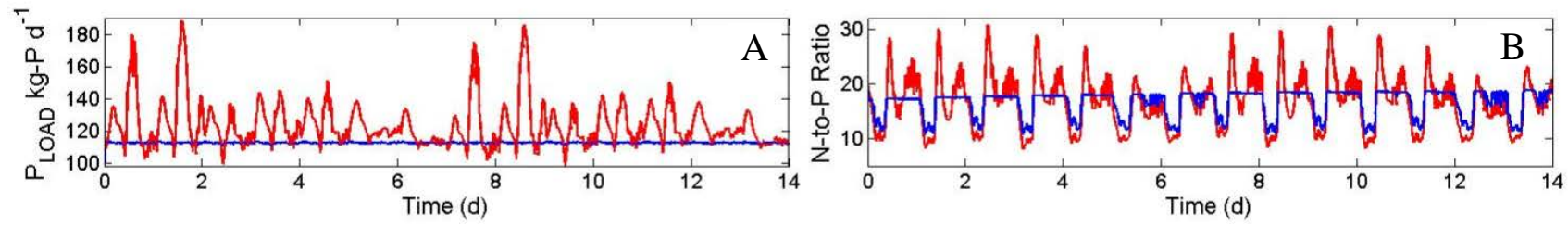

Figure 5 A) P-load fed to the PBR ; B) N-to-P ratio fed to the PBR using dynamic input disturbances in the CFS configuration of the EBP2R. The process response is presented under controlled conditions (blue) and without control (red). 


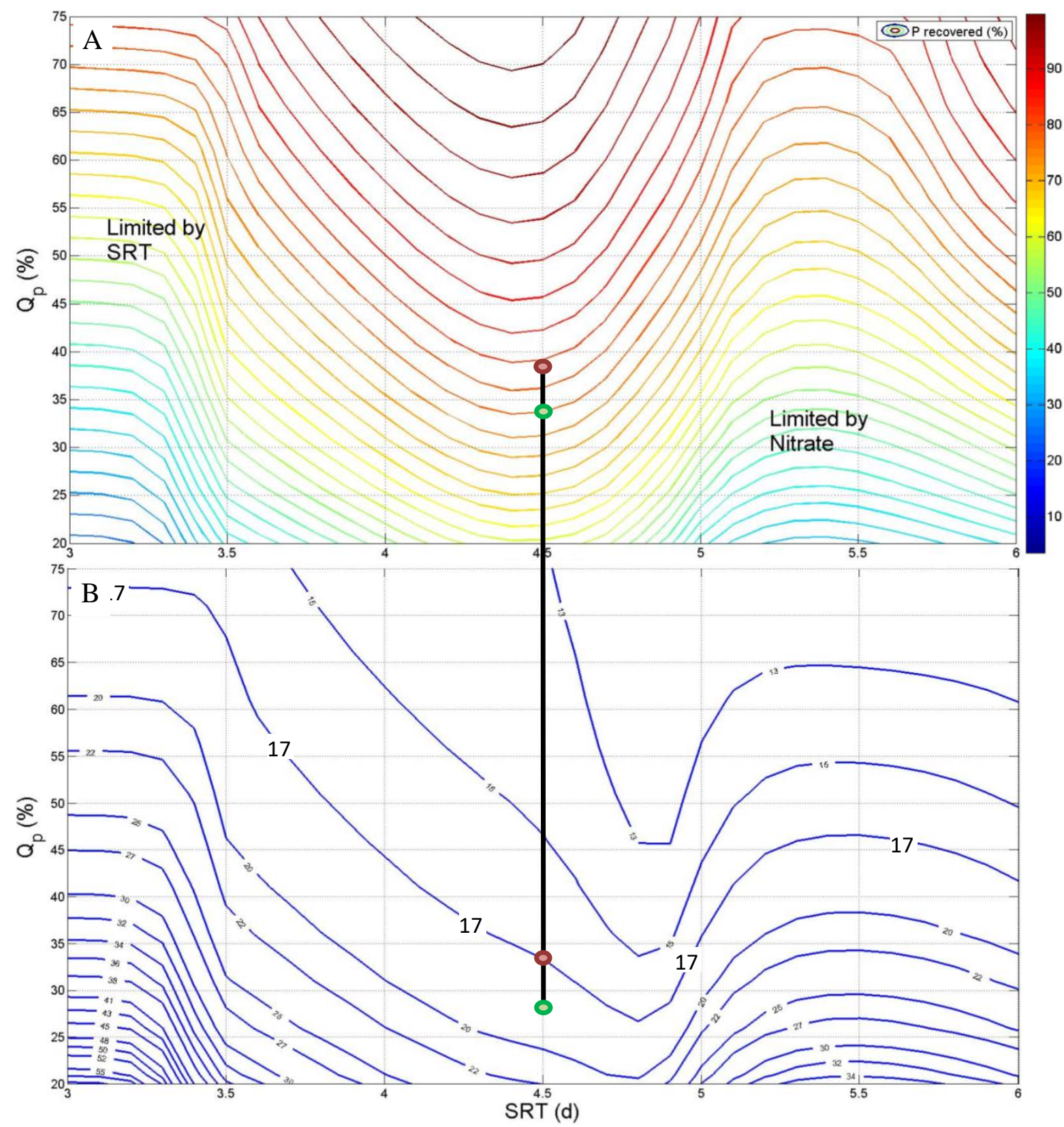

Figure 6 Process performance of the sequencing batch EBP2R system: A) Percentage of $P$ recovered from the influent (z-axis) as a function of the P-stream flow (y-axis) and the SRT (xaxis); B) N-to-P molar ratio in the EBP2R effluent (z-axis) as a function of the P-stream flow (yaxis) and the SRT (x-axis). Note that, in our study, the N-to-P ratio of 17 is the optimal nutrient balance for the algae considered to be cultivated in the downstream of the EBP2R. Red and green dots represent the phosphorus recovery (A) and N-to-P ratio in the effluent of the EBP2R (B) for the control structure 1 (CS-1) and control structure 2 (CS-2), respectively. 

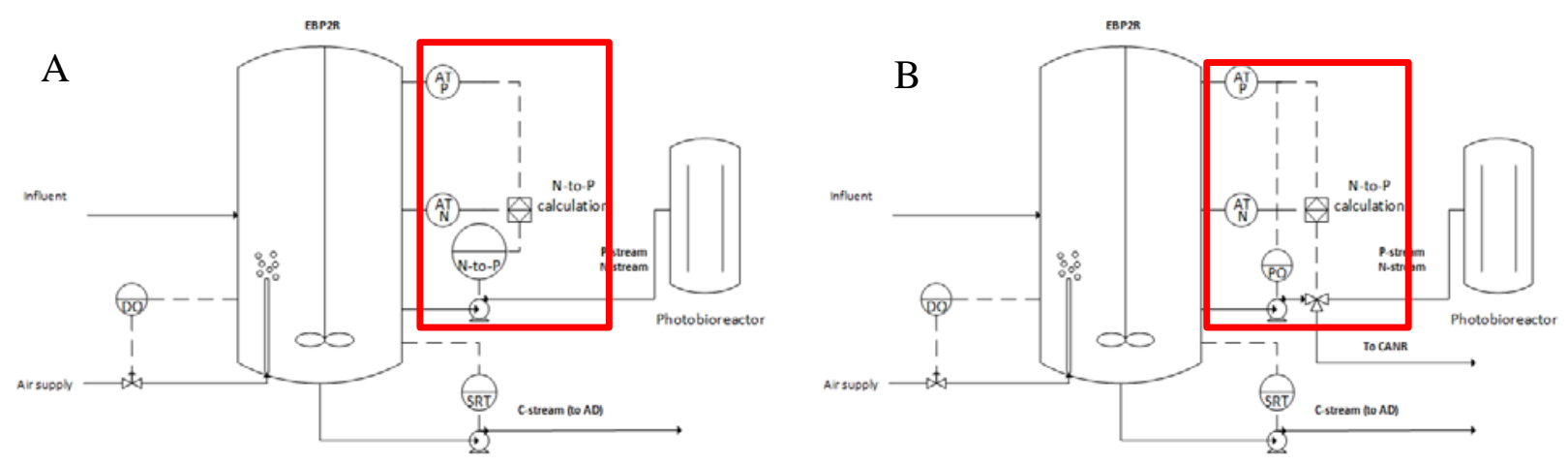

Figure 7 Layout of the control structure designed for the SBR EBP2R. A) control structure 1; B) control structure 2 . The red square highlights the difference between both control structures. Controllers are named by the CV they control (e.g. DO is the dissolved oxygen level controller). AT stands for analytical measurement and transmitter for nitrogen $(\mathrm{N})$ and phosphate $(\mathrm{P})$.
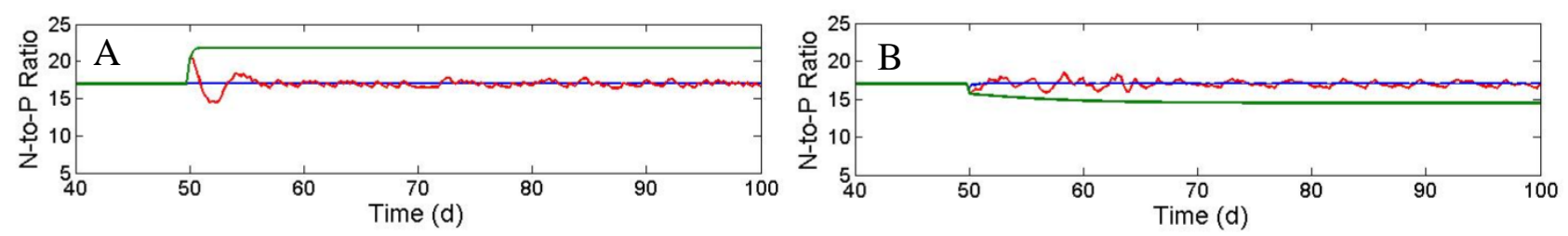

Figure 8 A) Effect of a step change in SBR of $+30 \%$ in the influent nitrogen; and B) effect of a step of $+20 \%$ in the influent phosphorus. The green line represents the open loop simulation; the red line represents the CS-1 performance; the blue line represents the CS-2 performance.

A
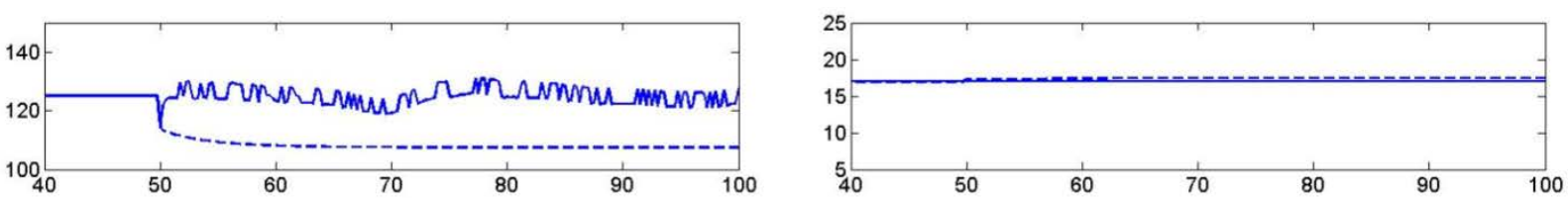

B
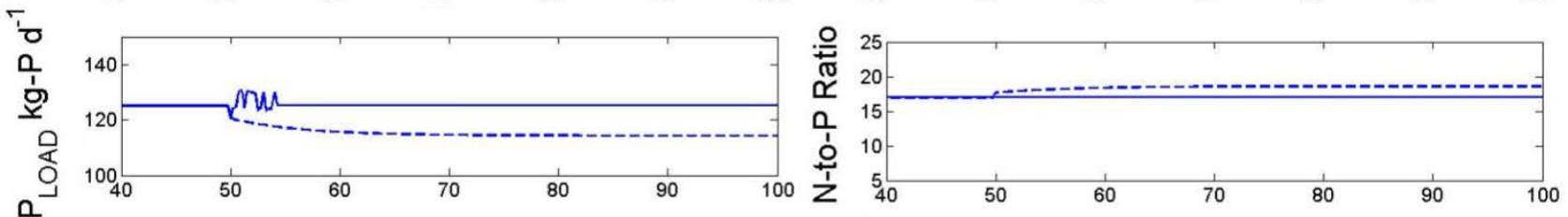

C
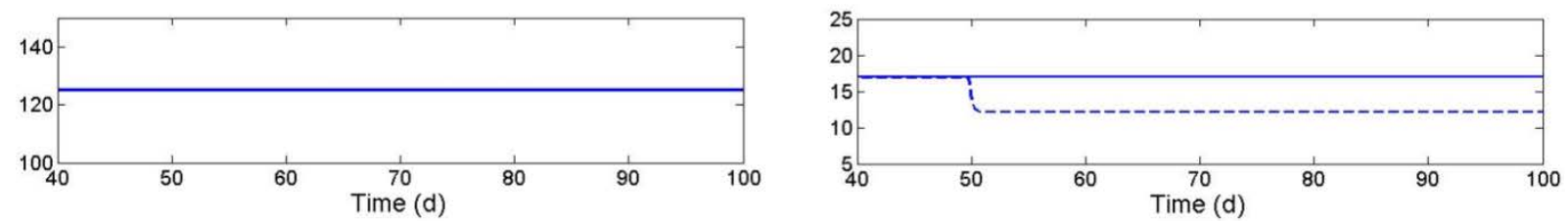

Figure 9 Response of the CS-2 of the SBR against step disturbances (step 5): A) Effect of a step change on the influent TCOD of $-20 \%$; B) effect of a $-20 \%$ step change of the influent phosphorus; and C) effect of a step change of $-30 \%$ on the influent ammonia. The full line represents the process response under controlled conditions and the dashed line the process response without control (open-loop). 

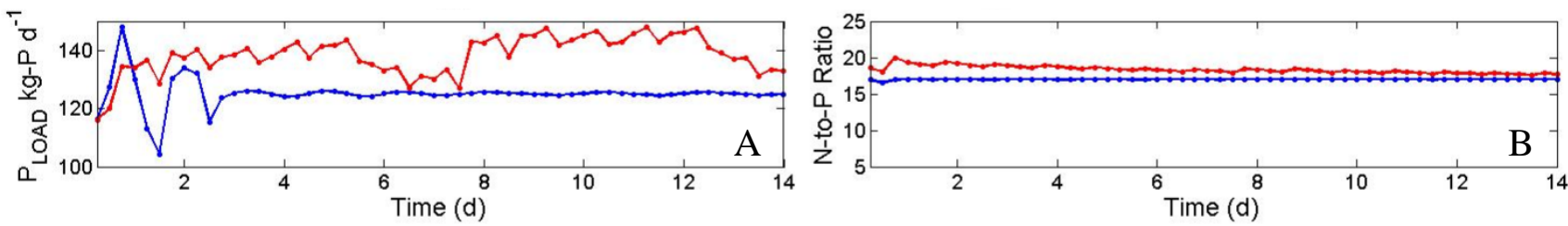

Figure 10: A) P-load fed to the PBR; B) N-to-P ratio fed to the PBR using dynamic input disturbances in the SBR configuration of the EBP2R. The process response is presented under controlled conditions (blue) and without control (red). 
Supporting Information

Control structure design for resource recovery using the enhanced biological phosphorus removal and recovery (EBP2R) activated sludge process

Borja Valverde-Pérez ${ }^{\mathrm{a}^{*}}$, José Manuel Fuentes-Martínez ${ }^{\mathrm{a}}$, Xavier Flores-Alsina ${ }^{\mathrm{b}}$, Krist V. Gernaey ${ }^{\mathrm{b}}$, Jakob Kjøbsted Huusom ${ }^{\mathrm{b}}$, Benedek Gy. Plósz ${ }^{\mathrm{a} *}$

${ }^{a}$ Department of Environmental Engineering, Technical University of Denmark, Miljøvej, Building 115, DK-2800, Kgs. Lyngby,Denmark (bvape@env.dtu.dk, beep@env.dtu.dk)

${ }^{b}$ Department of Chemical and Biochemical Engineering, Technical University of Denmark, Søltofts Plads, Building 229, DK-2800, Kgs. Lyngby, Denmark 


\section{SI-1-SBR operation and model details:}

Assuming that the reactor hold-up and all the flows have the same constant density, the global and individual species mass balances are:

$\frac{d V}{d t}=\sum_{n=1}^{i} F_{\text {in }}^{i}-F_{\text {out }}$

$\frac{d\left(V \cdot C_{j}\right)}{d t}=F_{\text {in }} \cdot C_{j, \text { in }}-F_{\text {out }} \cdot C_{j}+k_{L} a_{j} \cdot\left(C_{j}^{*}-C_{j}\right) \cdot V+r_{j} \cdot V$

where $F$ stands for the volumetric flows, $C$ for the concentrations, $r$ for the reaction rates and $V$ for the volume of the reactor. The subscripts IN and ouT stand for inflow and outflow respectively, $i$ for the different influent flows to the reactor, $j$ for the different components and superscript $*$ for the saturation concentration that would be in equilibrium with the gas phase.

The settling phase was assumed to be non-reactive and modeled as a point settler. Concentrations were constant along the settling phase:

$\frac{d\left(V \cdot C_{j}\right)}{d t}=0$

The SBR model was implemented in Simulink. A clock Simulink model block was used to make time available as an input to the hydraulic model, thereby allowing the transition between the different phases and mass balances. The different phases were simulated using the different mass balances (i.e. eq. 1, eq.2 and eq. 3) and also activating the different flow rates and the $\mathrm{k}_{\mathrm{L}}$ a during the phases where they were needed (e.g. influent flow rate was only active during the filling phase).

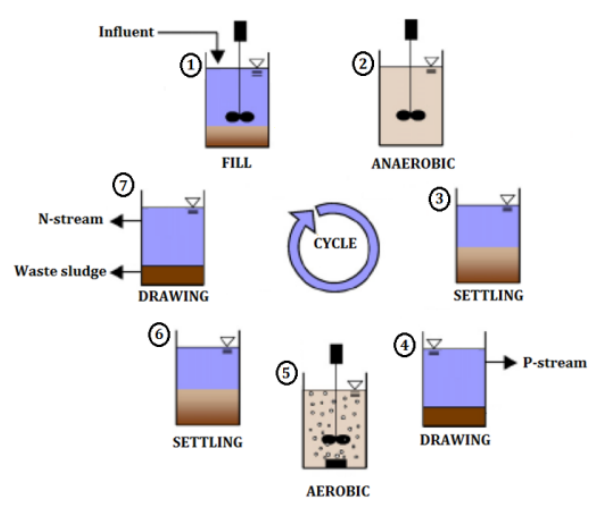

Figure S1: Operational scheme of the sequencing batch EBP2R configuration. 
SI-2-Dynamic influent characterization:
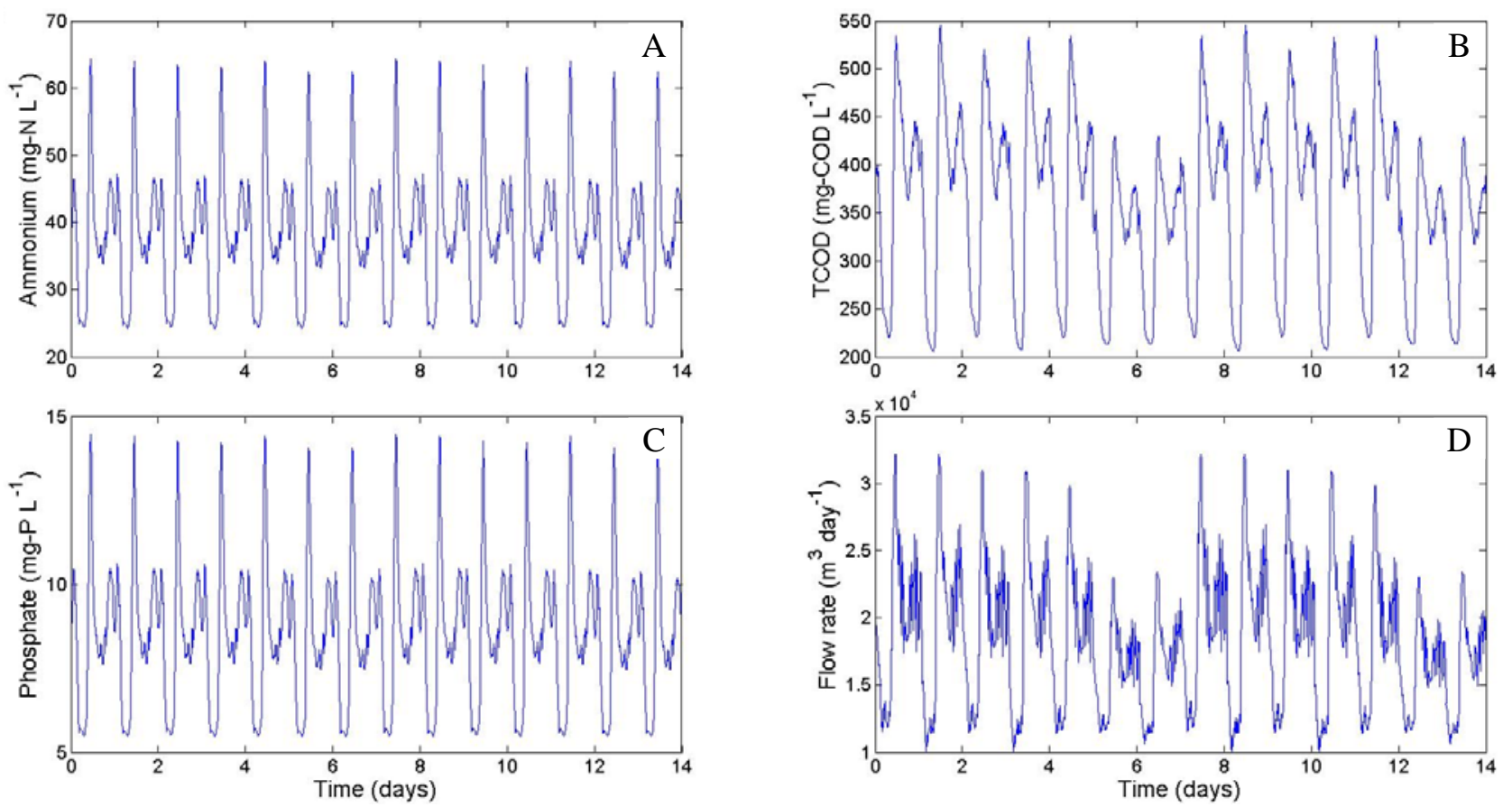

Figure S2: Influent to the EBP2R adapted from the BSM2 (Flores-Alsina et al., 2012): A) ammonium concentration; B) total chemical oxygen demand (TCOD); C) phosphate concentration; D) influent flow rate.

\section{SI-3-Positive step disturbances into the CFS EBP2R:}

A

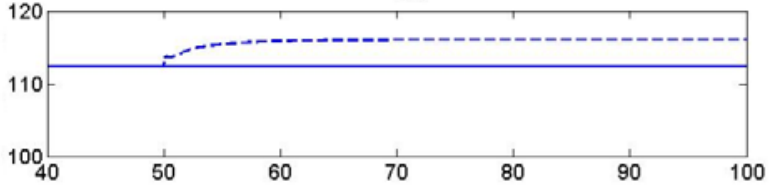

B

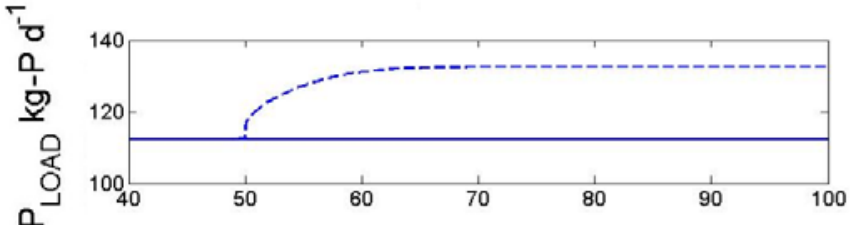

C

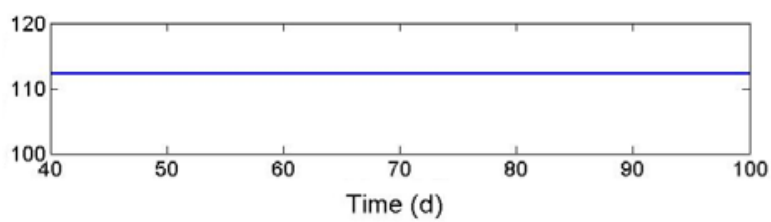

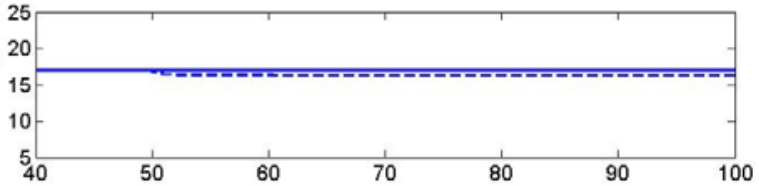
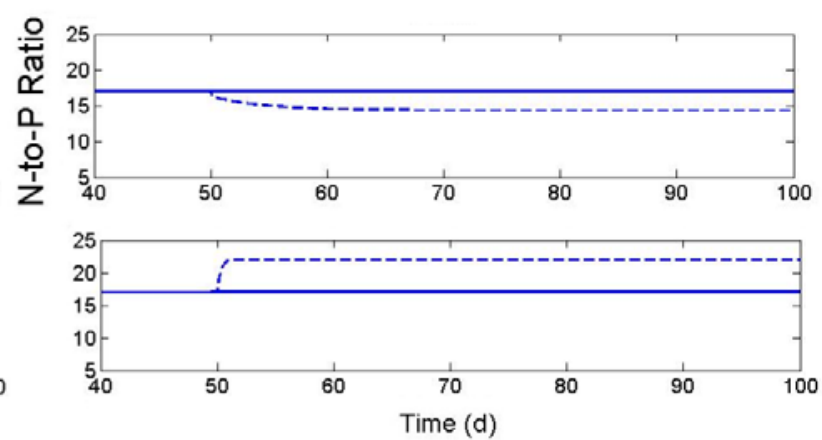

Figure S3: Response of the CFS to step disturbances (step 5): A) Effect of a step change on the influent TCOD of $-20 \%$; B) effect of a step change of $-20 \%$ on the influent phosphorus; and c) effect of a step change of $-30 \%$ on the influent ammonia. The full line represents the process response under controlled conditions and the dashed line the process response without control (open-loop). 
SI-4-Actuator response under dynamic influent conditions from BSM1 for the CFS EBP2R:

A

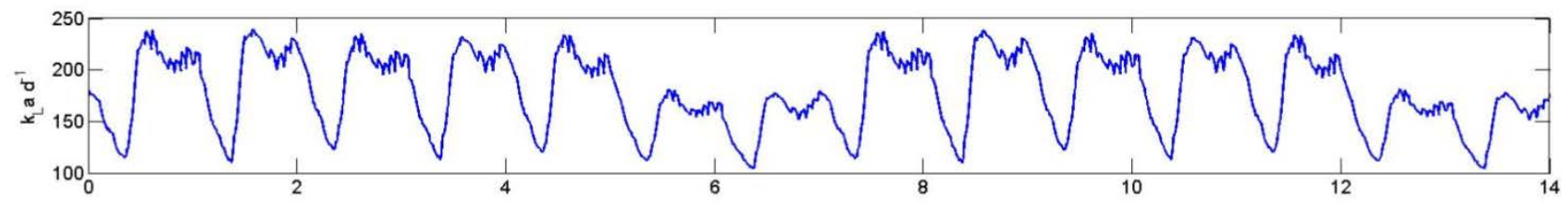

B
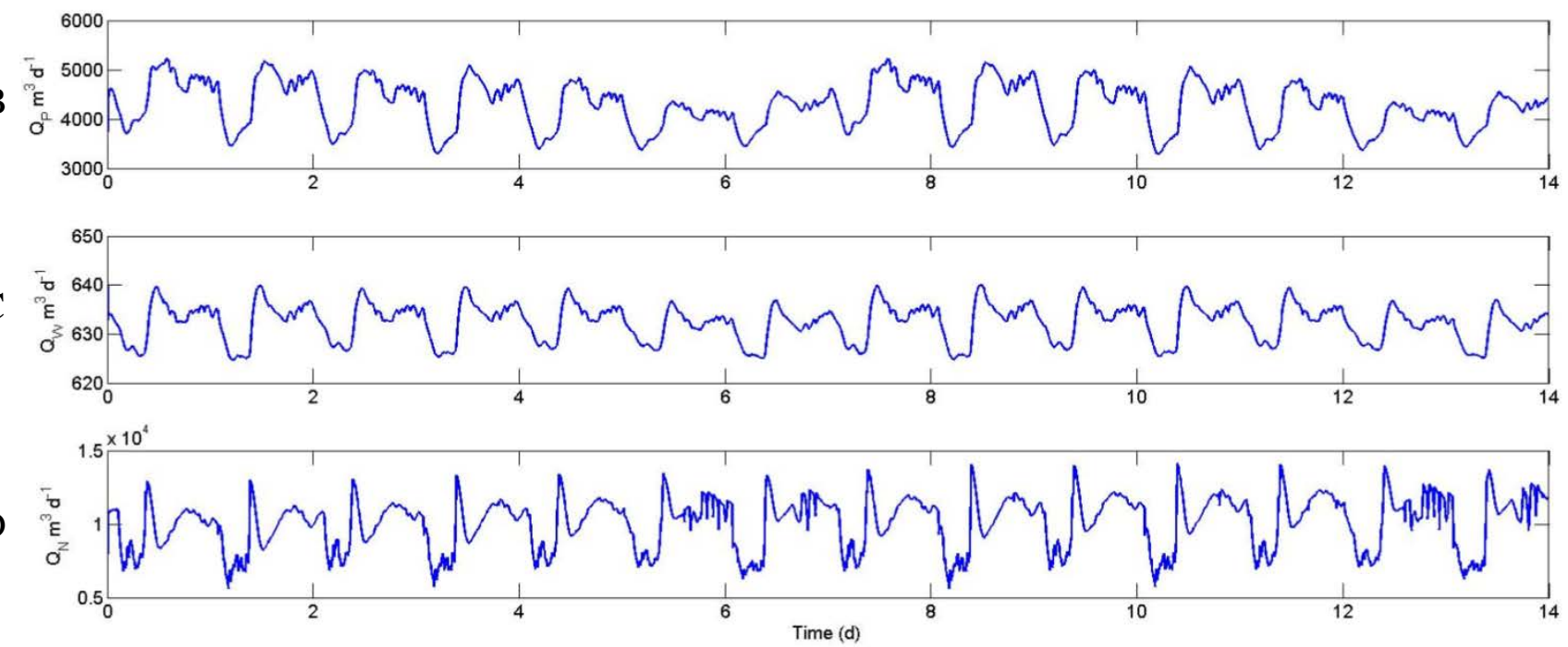

Figure S4: Response of the actuators of the CFS under dynamic influent conditions from BSM1 (step 6): A) $k_{L} a$; B) $Q_{p}$; C) $Q_{w}$; and D) $Q_{N}$.

SI-5-Positive step disturbances into the SBR EBP2R:

A
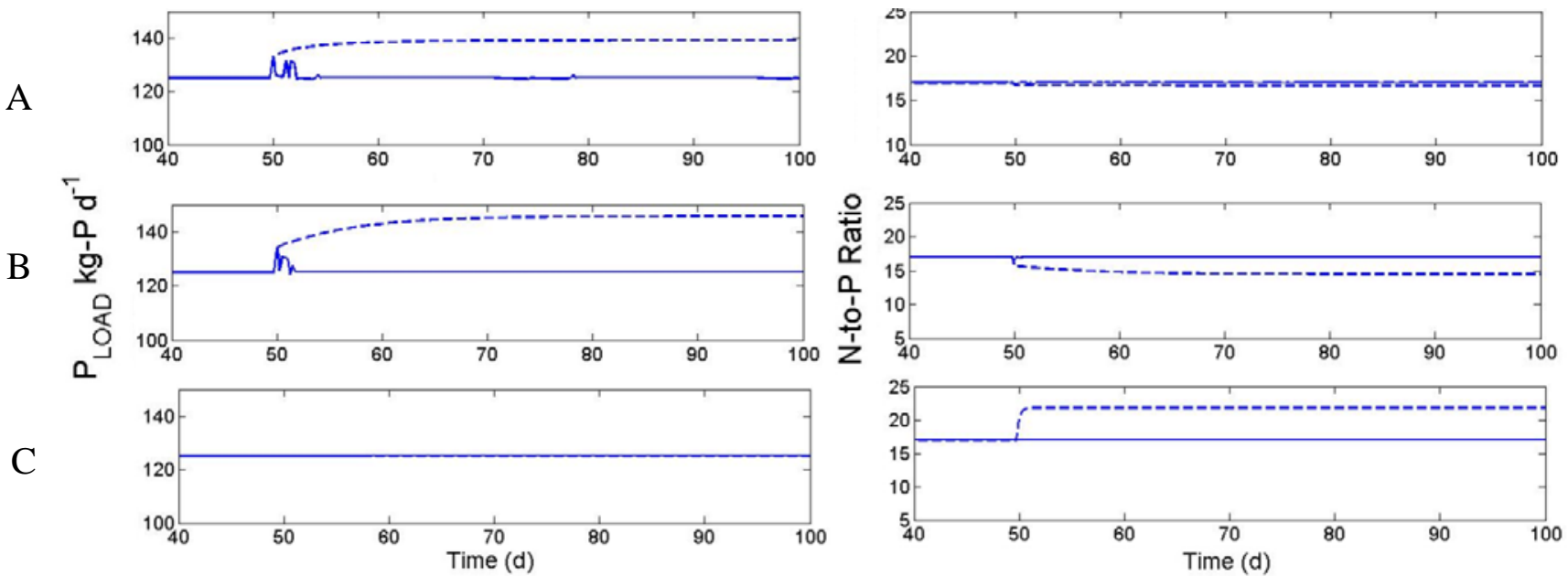

C

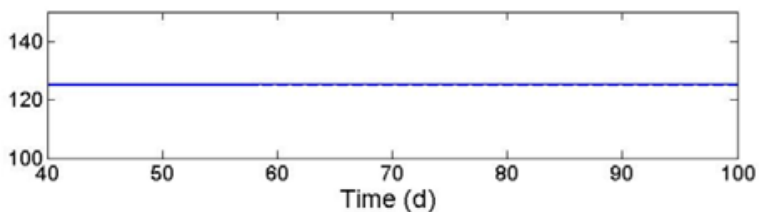

Figure S5: Response of the CS-2 of the SBR to step disturbances (step 5): A) Effect of a step change on the influent TCOD of -20\%; B) effect of a step change of -20\% on the influent phosphorus; and C) effect of a step change of $-30 \%$ on the influent ammonia. The full line represents the process response under controlled conditions and the dashed line the process response without control (open-loop). 
SI-6-Actuators response under dynamic influent conditions from BSM1 for the CFS EBP2R:

A

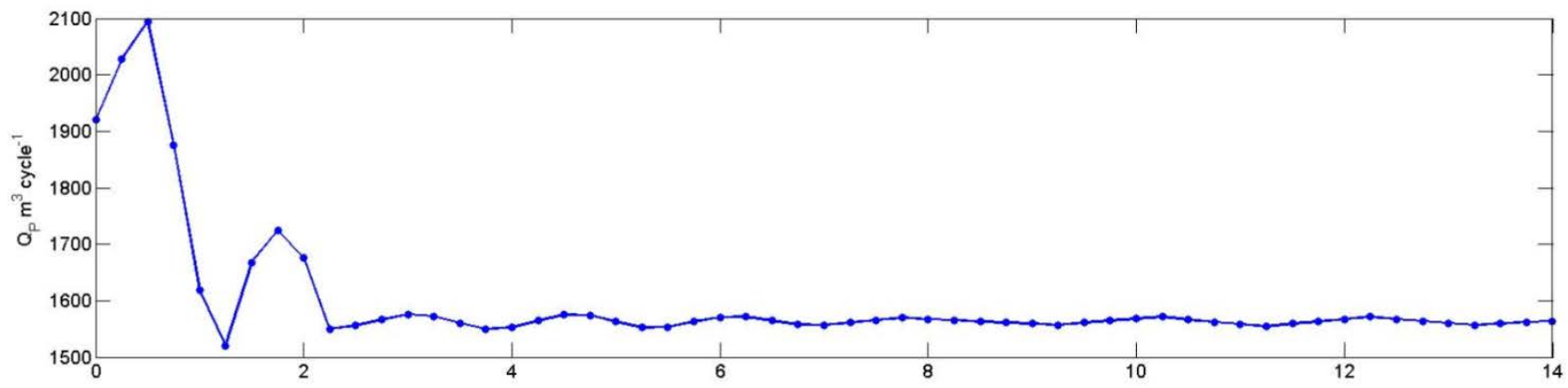

$\mathrm{B}$

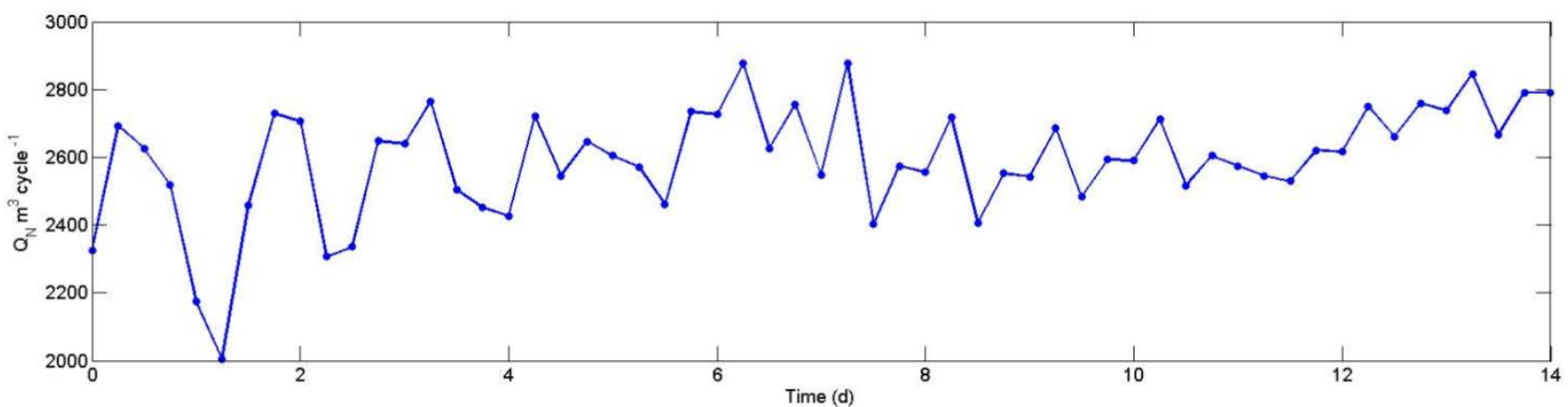

Figure S6: Response of the actuators of the CFS under dynamic influent conditions from BSM1 (step 6): A) Qp; and B) QN.

SRT is ideally controlled by wasting part of the sludge blanket by the end of the second anaerobic phase. The sludge blanket volume is assumed to be $20 \%$ of the total volume of the SBR. Therefore, $80 \mathrm{~m}^{3}$ of the sludge blanket are wasted to keep an SRT of 4.5 days.

SI-7-Illustration of the buffer effect by the equalization tank:
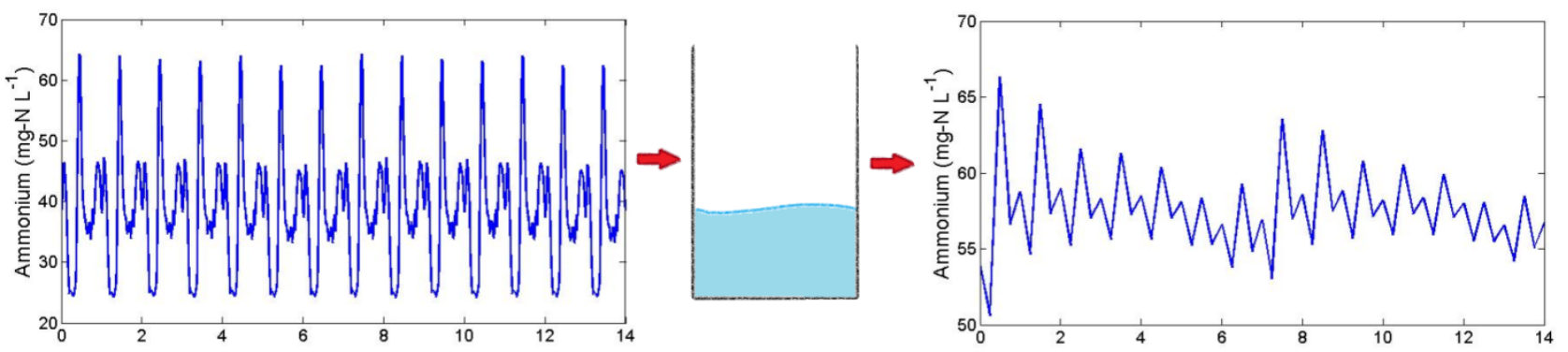

Figure S7: Effect of the equalization tank on the influent ammonium concentration. The influent to the treatment plant is presented on the left hand side of the tank. The figure on the right shows the concentration profiles obtained following flow equalisation before feeding the EBP2R. 